Journal of Fish Biology

June 2009, Volume 74, Issue 9, Pages 1891 - 1914

http://dx.doi.org/10.1111/j.1095-8649.2009.02298.x

(C) 2009 Wiley Blackwell Publishing, Inc. 2009 The Fisheries

Society of the British Isles
Archimer, archive institutionnelle de l'Ifremer http://www.ifremer.fr/docelec/

The definitive version is available at http://www3.interscience.wiley.com/

\title{
Estimates of the mortality and the duration of the trans-Atlantic migration of European eel Anguilla anguilla leptocephali using a particle tracking model
}

\author{
S. Bonhommeau ${ }^{1, *}$, D. Gascuel ${ }^{1}$, B. Blanke ${ }^{2}$, A.M. Tréguier ${ }^{2}$, N. Grima ${ }^{2}$, E. Rivot ${ }^{1}$, Y. Vermard $^{1}$, M. \\ Castonguay $^{3}$ and O. le Pape ${ }^{1}$
}

\footnotetext{
${ }^{1}$ UMR 985 INRAAgrocampus Ecologie et Santé des Ecosystèmes, Laboratoire d'Ecologie Halieutique, 65 rue de St Brieuc, CS 84 215, 35042 Rennes cedex, France

${ }^{2}$ Laboratoire de Physique des Océans, CNRS IFREMER IRD UBO, UFR Sciences et Techniques 6 avenue Le Gorgeu CS 93837, 29238 Brest CEDEX 3, France

${ }^{3}$ Pêches et Océans Canada, Institut Maurice La montagne, 850 route de la Mer, C.P. 1000, Mont Joli, Québec, Canada, G5H $3 Z 4$

*: Corresponding author: S. Bonhommeau, Tel.: +33 4995732 66; fax: +33 4995732 95; email address : sylvain.bonhommeau@ifremer.fr
}

\begin{abstract}
:
Using Lagrangian simulations, based on circulation models over three different hydroclimatic periods in the last 45 years in the North Atlantic Ocean, the trans-Atlantic migration of the European eel Anguilla anguilla leptocephali was simulated via the passive drift of particles released in the spawning area. Three different behaviours were modelled: drifting at fixed depth, undergoing a vertical migration or choosing the fastest currents. Simulations included mortality hypotheses to estimate a realistic mean migration duration and relative survival of $A$. anguilla larvae. The mean migration duration was estimated as 21 months and the mortality rate as 3.8 per year, i.e. $<0.2 \%$ of $A$. anguilla larvae may typically survive the trans-Atlantic migration.
\end{abstract}

Keywords: Lagrangian modelling • leptocephalus mortality $\bullet$ migration duration 


\section{INTRODUCTION}

The European eel (Anguilla anguilla L.) is a catadromous fish that goes through a long oceanic spawning migration, from continental growth habitats more than $6,000 \mathrm{~km}$ across the Atlantic Ocean to the Sargasso Sea. Eel larvae (leptocephali) then return, metamorphosing as

25 they reach the continental shelf into glass eels that settle in European and North African freshwaters, estuaries and coastal waters, from Mauritania to the Polar Circle (Schmidt, 1923; Tesch, 2003).

The oceanic larval phase of European eels is of great importance in understanding eel population dynamics. As for many marine fish species, the major source of mortality occurs

30 during the larval stage (Hjort, 1914). The oceanic phase determines the dispersion over the coastal regions and the freshwater habitats (Kettle \& Haines, 2006). The migration duration is certainly one of the most critical and controversial features of the oceanic biology of eel larvae. It is related to eel larval oceanic trajectories and mortality, and hence it determines dates and areas of arrival at the coast. It also determines our ability to understand how

35 recruitment is linked to environmental fluctuations. This is critical in a context where major changes in oceanic conditions are recorded and known to impact fish populations (Beaugrand \& Reid, 2003; Lehodey et al., 2006). Recruitment data have been compared to environmental factors such as large-scale oceanic and climate indices (Knights, 2003; Friedland et al., 2007; Bonhommeau et al., 2008; Kettle et al., 2008a). Fluctuations in sea temperature and primary

40 production in the spawning area have been shown to be related to glass eel recruitment (Knights, 2003; Bonhommeau et al., 2008). However, all these studies used recruitment indices based on glass eel arrivals. Because oceanic environmental conditions must affect leptocephali several months earlier than glass eel arrivals, time lags have to account for migration duration to link environmental descriptors to glass eel recruitment. Results still 
45 remain conditioned by the assumption made about migration duration, e.g. 1-year lag for Friedland et al. (2007), environmental conditions integrated over 2.5 - 3 years for Knights (2003) and a 2.5 -3 year lag for Bonhommeau et al. (2008).

These hypotheses rely on different estimates depending upon the methods used. While cohort analyses (Schmidt, 1922), otolith macrostructure analyses (van Utrecht and Hollebom 50 (1985) and particle-tracking models (Kettle \& Haines, 2006) show a long migration duration (more than two years), the analyses of the otolith microstructure estimate that the migration duration is shorter than 1 year (Lecomte-Finiger, 1992; Wang \& Tzeng, 2000). The hypotheses proposed to explain a short migration duration is a hypothetical active and oriented swimming of eel leptocephali (see Bonhommeau et al., accepted, for further 55 descriptions). Improving our knowledge of the oceanic migration duration is a prerequisite to a better understanding of the effects of the oceanic environment on eel larvae and subsequent recruitment.

Recently, it has been shown how general circulation models may provide insights to better understand larval trans-oceanic migration. Kettle \& Haines (2006) used Lagrangian

60 simulations over a 4-year period (1993-1996) to estimate the migration duration and pathways of European eel larvae and found a 2-year duration to $25^{\circ} \mathrm{W}$. However, Kettle \& Haines (2006) used fixed-depth passively-drifting particles to analyse migration routes and duration. This assumption remains questionable as leptocephali show vertical diurnal migrations (e.g. Castonguay \& McCleave, 1987) and might be able to select faster current velocities at 65 different depths. Here the hypothesis of strict passive and fixed-depth drift of particles is relaxed. To do so, other particle trajectories are explored using two other behaviours (although biologically unrealistic) that enable assessment of their impact on migration duration and mortality. These issues are addressed in the present study by comparing results 
from three different behaviours of the particles: $(i)$ particles drifting at fixed-depth as in Kettle

70 \& Haines (2006), (ii) particles undergoing a vertical diurnal migration between 300m and 50m as observed in the wild (Castonguay \& McCleave, 1987), (iii) particles drifting at the depth where the velocity of currents (whatever the direction) is the highest. Moreover, Kettle \& Haines (2006) recognized that their approach suffered from a critical drawback in that it did not account for mortality of particles during migration; with no mortality, even the slowest

75 particles will succeed in reaching the 'finishing' line and the mean duration will be pushed toward unrealistic high values. Conversely, if mortality is included, the slowest particles have a greater chance of dying than the fastest ones and a strong negative correlation would be expected between mean migration duration and mortality.

In this paper, this issue is addressed by combining the results of Lagrangian

80 simulations with current knowledge gathered from the literature which allows estimation of the mortality of leptocephali. The different mortality estimates over the whole life cycle, except the leptocephalus stage, enabled estimation of the mortality of eel leptocephali under a steady-state hypothesis of eel population, i.e. no increase nor decrease of the population size. The range of credible values for the mortality during the oceanic larvae stage is hence restricted. This, in turn, allows for drastic restrictions of the range of estimated migration duration from Lagrangian simulations, helping to provide a more realistic estimate of the mean migration duration.

\section{MATERIALS AND METHODS}

\section{CIRCULATION MODELS}


scientific community involved in realistic basin-scale ocean modelling. Simulations were possible over a period of 45 years. The Drakkar model (http://www.ifremer.fr/lpo/drakkar) is based on the NEMO/OPA numerical code (Madec et al., 1998) and is useful because of the

95 duration of the simulation (1958 to 2004), which allows it to address the interannual variability of trajectories over decadal time scales. The model configuration is global. The model configuration is global, using the ORCA025 grid (a tripolar grid with a $1 / 4^{\circ}$ horizontal resolution at the equator). Barnier et al. (2006) described this configuration and showed its good performance in representing strong currents and eddy variability, even in comparison

100 with higher resolution models. The water column is divided into 46 levels, with grid spacing ranging from $6 \mathrm{~m}$ near the surface to $250 \mathrm{~m}$ at the bottom. The simulation was run using state of the art atmospheric data (a blend of satellite products and ERA40 6-hourly winds, temperature and humidity). The Drakkar model is a so-called 'fully prognostic' model, which means that it does not use assimilated ocean data (satellite altimetry, in-situ temperature or

105 salinity) and therefore can be substantially different from observations in some areas, e.g. subpolar regions (Tréguier et al., 2005). Fortunately those biases are less pronounced in the subtropical gyre, including the Sargasso Sea. To reduce file size and to centre on the North Atlantic Ocean, simulations were restricted to a subregion ranging from 82 to $6^{\circ} \mathrm{W}$ and 10 to $60^{\circ} \mathrm{N}$. Since the observed depth selected by leptocephali ranges between 50 and $300 \mathrm{~m}$ (e.g.

110 Castonguay \& McCleave, 1987), the oceanic model was limited to the top 24 levels (3 to 989 m). To avoid the early spin-up phase of the model, the study was restricted to the period 19602004 of the simulation. Circulation fields were time-mean archived every 5 days.

\section{LAGRANGIAN SIMULATION DESIGNS}


The Ariane tool was used, as developed by B. Blanke and N. Grima, Laboratoire de

115 Physique des Océans, CNRS-IFREMER-IRD-UBO, Brest, France (http://www.univbrest.fr/lpo/ariane). It is a FORTRAN code dedicated to the computation of 3D streamlines in a given velocity field (as the output of an Ocean General Circulation Model) and subsequent water mass analyses. The Ariane tool takes advantage of ' $C$ ' grids used for horizontal discretization in numerical codes such as NEMO/OPA to compute analytically trajectories

120 from model outputs. This algorithm calculates true trajectories for a given stationary velocity field. The Ariane tool has been used successfully in several studies to derive relevant information about basin-scale or global scale circulation patterns (e.g., Blanke \& Raynaud, 1997; Blanke et al., 1999; Blanke et al., 2001). For each simulation year, passive drifters were released in each model grid cell, i.e. every $1 / 4$ degree and in each vertical level in an area

125 enclosing the assumed spawning area of eels in the Sargasso Sea (Fig. 1 and Fig. 2 in McCleave \& Kleckner, 1987). Particles were released every 15 days throughout the year. Although spawning occurs during late winter and spring (e.g. McCleave et al., 1987), particles were released throughout the year to explore a wider range of possible trajectories. This enabled investigation of possible seasonal variations in migration duration. A total of 130 1,972,608 particles were released each year. Particles were allowed to drift over a 5-year period, which is long enough to encompass the probable maximum migration duration of European eel larvae, according to the different estimates discussed earlier.

[Figure 1 about here.]

Output files of Lagrangian simulations included position (longitude, latitude, depth) 135 and time for each particle. Particles were considered as having 'succeeded' in their migration when crossing longitude $20^{\circ} \mathrm{W}$, whatever the latitude (see Fig.1). This finish line is more 
eastward than the $25^{\circ} \mathrm{W}$ limit chosen by Kettle \& Haines (2006). Since the aim of the study was to estimate the mean migration duration, the finish line has to be as close as possible to the actual arrival area of eel leptocephali to compare to current estimates based on glass eel 140 recruitment to continental habitats. However, $20^{\circ} \mathrm{W}$ is a reasonable limit since longitudes to the east correspond to the continental slope which is not as well-resolved by the physical model as the open ocean. Moreover, the design of the Lagrangian simulations was unable to represent selective tidal-stream transport or active swimming of glass eels when they reach the shelves (e.g. Gascuel, 1986).

145 The North Atlantic Oscillation index (NAO-index; Hurrell, 1995) is a large scale and integrative index that is derived from the difference between sea level pressure in Lisbon, Portugal and Reykjavick, Iceland. It is correlated with oceanic transport via the strength (Transport index, Curry \& McCartney, 2001) and latitude (Gulf Stream index, Taylor \& Stephens, 1998) of the Gulf Stream. For comparative purposes, three periods of low, average 150 and high NAO were selected for simulations, i.e. 1960-1964 (mean NAO index= -1.7), 19731977 (0.9), and 1986-1993 (3.2). Thus 18 years of particle releases were simulated in total, with the longest period (8 years) encompassing the period of increasing NAO index but also the decline in eel recruitment (Bonhommeau et al., 2008).

The behaviour of leptocephali during their transatlantic migration may impact on their 155 migration duration and mortality. Therefore, three particle behaviours were implemented in Lagrangian simulations. The first assumed a fixed depth drift for all particles released at each vertical level of the reduced model. It is not grounded on biological observations but enabled comparison with Kettle \& Haines (2006). In a second experiment, a vertical diurnal migration was implemented, making particles flip every 12 hours from $300 \mathrm{~m}$ to $50 \mathrm{~m}$, as described in 160 Castonguay \& McCleave (1987). This experiment mimics behaviour of eel larvae in the wild 
as leptocephalus collections have been shown to have a diurnal migration depending on their length (Castonguay \& McCleave, 1987). Until the length of $7 \mathrm{~mm}$, they are uniformly distributed over the 300m upper layers (Schmidt, 1922; Schoth \& Tesch, 1983; Castonguay \& McCleave, 1987). Thereafter, a diurnal vertical migration is observed from $300 \mathrm{~m}$ in daytime and 50m at night (Schmidt, 1922; Castonguay \& McCleave, 1987; McCleave, 1993; McCleave et al., 1998). Although these different behaviours during the earliest life stages of eel leptocephali and afterwards have been observed, it was decided to implement the daily vertical migration from $300 \mathrm{~m}$ to $50 \mathrm{~m}$ as soon as particles were released. It should be pointed out that this second experiment is considered the most realistic one. current velocity at each time step. The experiment may be unrealistic as there is no evidence that a leptocephalus can sense the direction and speed of a current in open water without fixed reference points. However, this experiment is a way to assess the potential impact of a different behaviour on migration duration and mortality.

Denoting $M$ as the instantaneous mortality rate per year, the cumulative mortality from 0 to time $t$ is then $1-\mathrm{e}^{-M . t}$ (e.g. Peterson \& Wroblewski, 1984). For each value of $M$, Lagrangian simulations provide a histogram of particle migration duration $d$, interpreted here as a probability distribution:

$$
\pi_{L}(d \mid M)
$$

Combined with an a priori distribution for $M$, that was chosen as uniform on the range $[0,10]$, a joint distribution for $(M, d)$ can be obtained: 


$$
\pi_{L}(M, d)=\pi(M) \cdot \pi_{L}(d \mid M)
$$

The key idea is to combine this joint distribution with current knowledge gathered in 185 the literature to obtain a new distribution $\pi(M, d)$ confined to a more restricted range of value of $(M, d)$. This is achieved by the multiplication of the joint distribution $\pi_{L}(M, d)$ by a second distribution independently derived from current knowledge about eel ecology (see hereinafter) denoted $\pi_{E}(M, d)$ :

$$
\pi(M, d)=\pi_{L}(M, d) \cdot \pi_{E}(M, d)
$$

190 Once obtained, the marginal distribution of the migration duration $d$ can be calculated by integration over the possible values of $M$ and vice versa:

$$
\begin{aligned}
& \pi(d)=\int_{d} \pi(M, d) d d \\
& \pi(M)=\int_{M} \pi(M, d) d M
\end{aligned}
$$

Because the joint distribution was estimated on a discrete grid, the computation of marginal 195 distributions is straightforward.

\section{IMPLEMENTING MORTALITY IN LAGRANGIAN SIMULATIONS}

To assess how the histogram changes with $M$, the following procedure has been used. The frequencies of migration duration was assessed by classes of 1 month for months $d_{i}=1, \ldots, n$. Let $\left\{f_{d_{i} 0}\right\}_{i=1, \ldots, n}$ denote the histogram formed by the frequencies, $f_{d_{i} 0}$, of

200 particles with migration durations $d_{i}$ obtained from Lagrangian simulation without any mortality $(M=0)$. For each value of $M$, the new histogram of migration durations denoted 
$\left\{f_{d_{i} M}\right\}_{i=1, \ldots, n}$ was simply obtained by weighting the initial frequency by the survival rate up to $d_{i}$ :

$$
f_{d_{i} M}=f_{d_{i} 0} \cdot e^{-M \cdot d_{i}} \text { for } \mathrm{i} \text { in } 1, \ldots, n
$$

205 The new histogram $\left\{f_{d_{i} M}\right\}_{i=1, \ldots, n}$ is then interpreted as the conditional probability distribution $\pi_{L}(M, d)$, estimated on a 1-month interval grid. Lagrangian simulations are deterministic: particles released at the same location and at the same time have the same trajectory. It could have been possible to implement a stochastic mortality rule for each particle in the simulation. However, as the simulations are deterministic, equation 6 provides an exact evaluation of the expected mean of the frequencies in the class $d_{i}$ given the instantaneous mortality $M$.

\section{COMBINING KNOWLEDGE ABOUT EEL ECOLOGY}

The joint distribution $\pi_{E}(M, d)$ can be constructed from the combination of knowledge gathered in the literature. We rely on a steady state hypothesis. For any species with a default sex ratio of $1: 1$, i.e. $50 \%$ female and $50 \%$ male, the rule 1 female gives 2

215 offspring (i.e. 1 male and 1 female) is necessary to maintain the steady state of their population (Jung et al., 2008). An equilibrium sex-ratio 1:1 was assumed for the European eel at the population scale. Because it is a semelparous species, the steady-state hypothesis implies that the product of the female eel fecundity by all the survival rates of their offspring until they spawn must result in 2 individuals (Eq. 7). This equation implies that, among all of

220 the eggs produced by a female, only two individuals survive and reproduce. In this case study, it could be formulated as: 


$$
2 \approx F e c \cdot \xi \cdot \alpha \cdot \beta \cdot \gamma \cdot \eta
$$

where $\mathrm{Fec}$ is the fecundity of female eels, $\xi$ the hatching rate, $\alpha$ the survival rate of leptocephali from hatching to glass eel stage, $\beta$ the survival rate of glass eels, $\gamma$ the survival 225 rate of juvenile eels (continental stage) equal to $\mathrm{e}^{-M a \cdot d a}$, where $M_{a}$ is the annual mortality rate and $d_{a}$ is the age of pre-migrating silver eels, and $\eta$ is the rate of silver eels that successfully return to the Sargasso Sea and mate.

Estimates for all parameters in equation (Eq. 7) can be found in the literature, except for the parameter $\alpha$, the leptocephalus survival rate and $\eta$ the rate of silver eels that succeed 230 to mate in the Sargasso Sea. Equation 7 enables us to express $\alpha$ as a function of the other parameters:

$$
\alpha \approx \frac{2}{F e c \cdot \xi \cdot \beta \cdot \gamma \cdot \eta}
$$

Regarding literature data (Table I), the following values were selected: $F e c=1.5 .10^{6}$ eggs, hatching survival rate $=20 \%$, glass eel survival rate $=10 \%, M=0: 14$, age of mature eels $=10$

235 years and survival rate during the spawning migration $=30 \%$ (estimated from a 0.5 year migration duration to reach the Sargasso Sea and a high mortality rate of 0.7 ).

[Table I about here.]

To account for uncertainties about these point estimates, a probability distribution was assigned to each parameter (Fig. 2). Beta distributions were set for $\xi, \beta, M_{a}$, and $\gamma$ as they 240 range between 0 and 1 . Gamma distributions were set to the fecundity $(F e c)$ and the age of spawners $\left(d_{a}\right)$ as these parameters have to be positive. These different distributions were combined as in Eq. 8 to provide the uncertainty about the survival rate of leptocephali.

[Figure 2 about here.] 
From equation 8 , an expression of the migration duration $d$ (time for eel larvae to reach $20^{\circ} \mathrm{W}$ ) can be derived given the instantaneous mortality of eel larvae $M$. Indeed, $\alpha$ is a survival rate and can be written as $\alpha=\mathrm{e}^{-M \cdot(d+d r e m)}$, where $M$ is the natural mortality of leptocephali and $d+d_{r e m}$ is the total duration from hatching to glass eel reaching the coast. This total duration is the sum of the migration duration to $20^{\circ} \mathrm{W}(d)$ and the time needed to reach the continental slope and metamorphose, $d_{\text {rem. }}$. The metamorphosis is estimated to take between 1 and 3

250 months (Lecomte-Finiger, 1992; Wang \& Tzeng, 1998; Arai et al., 2000; Wang \& Tzeng, 2000).

One to two months were arbitrarily added to account for the time to reach the continental shelves and cover the 1000 to $1500 \mathrm{~km}$ remaining although it is difficult to estimate since the larvae can arrive from Ireland $\left(1000 \mathrm{~km}\right.$ from the $\left.20^{\circ} \mathrm{W}\right)$ to Norway $255\left(2500 \mathrm{~km}\right.$ from the $\left.20^{\circ} \mathrm{W}\right)$. This estimation stems from the mean speed of currents in that area that is about $0.2 \mathrm{~m} \mathrm{sec}^{-1}$ (Fratantoni, 2001). To cover $1000 \mathrm{~km}$ directly with a mean speed of $0.2 \mathrm{~m} \mathrm{sec}^{-1}$ would take 58 days. Thus, $d_{\text {rem }}$ was considered to be uniformly distributed between 2 to 5 months (time to reach the continental slope and metamorphose). The following expression can be derived:

$$
e^{-M \cdot\left(d+d_{r e m}\right)} \approx \frac{2}{F e c \cdot \xi \cdot \beta \cdot e^{-M_{a} \cdot d_{a}} \cdot \eta}
$$

that gives

$$
d \approx \frac{\log \left(\frac{2}{F e c \cdot \xi \cdot \beta \cdot e^{-M_{a} \cdot d_{a}} \cdot \eta}\right)}{-M}-d_{r e m}
$$


Using Monte Carlo simulations, Eq. 10 was used to derive a sampling based estimation of the conditional probability of $d$ given $M$, that is $\pi_{E}(M \mid d)$. Combined with a uniform

265 distribution on $M$, we obtained the joint distribution $\pi_{E}(M, d)$ that is needed to be combined with the Lagrangian distribution $\pi_{L}(M, d)$.

\section{SENSITIVITY ANALYSIS}

The two distributions $\pi_{L}(M, d)$ and $\pi_{E}(M, d)$ were combined (i.e. multiplied) to obtain the final joint estimation of the mortality $M$ and migration duration $d$. To assess the

270 soundness of results, the elasticity of $\bar{d}$, the geometric mean of the marginal distribution of the migration duration $d$, and $\bar{M}$, the geometric mean of the marginal distribution of the annual mortality $M$ were calculated regarding the different parameters (Table I). Elasticity is the ratio of the proportional change in one variable with respect to proportional change in another variable. It illustrates the relative change of $\bar{d}$ and $\bar{M}$ when a parameter increases

275 by a small percentage (here, $10 \%$ ) and when all other parameters are kept at their standard values.

\section{RESULTS}

\section{ESTIMATION OF THE LEPTOCEHALUS SURVIVAL RATE}

The probability distribution of leptocephalus survival rate $(\alpha)$ obtained from Monte

280 Carlo simulations has a lognormal distribution. A point estimate (geometric mean of the distribution) for the leptocephalus survival rate is found near $0.15 \%$ (Fig. 3).

[Figure 3 about here.] 
DISTRIBUTION, DEPTH-DRIFT, AND DEPARTURE AREA AND MONTH OF SIMULATED PARTICLES

285

The majority of particles arriving at $20^{\circ} \mathrm{W}$ were distributed between 40 and $55^{\circ} \mathrm{N}$, with a peak at $50^{\circ} \mathrm{N}$ (Fig. 4). Another peak appears in the North Africa area $\left(30-35^{\circ} \mathrm{N}\right)$. A more northerly peak was also observed $\left(57-62^{\circ} \mathrm{N}\right)$. The migration pathways follow the Gulf Stream and North Atlantic drift (Fig. 5). Some particles that drifted more than 2 years followed the

290 Azores Current and arrived at Moroccan latitudes (Fig. 5). It is noteworthy the majority of particles arrived at Western Europe latitudes as illustrated in Figs. 4 and 5. The main departure area of arriving particles was located in the Western Sargasso Sea $\left(75^{\circ}-65^{\circ} \mathrm{W}\right.$ and $22^{\circ}-30^{\circ} \mathrm{N}$; Fig. 5). The same patterns of departure and arrival areas were observed for the three experiments, i.e. fixed-depth, vertical migration, or faster current choice. Regarding the

295 fixed-depth experiment, the depth range of particles crossing the $20^{\circ} \mathrm{W}$ was between $400 \mathrm{~m}$ and the surface. The Gaussian distribution of these depths had a mode at $200 \mathrm{~m}$. The departure month of particles that reached the $20^{\circ} \mathrm{W}$ without mortality was uniformly distributed over the year. The same number of particles arrived at $20^{\circ} \mathrm{W}$ whatever the departure month (Fig. 6, solid line). However, when applying an annual mortality rate (3.8),

300 the distribution of departure months exhibited a clear peak from March to June (Fig. 6, dashed line). For instance, three times as many particles released in April (the estimated spawning season, McCleave, 2008) reached the $20^{\circ} \mathrm{W}$ compared to those released in July.

[Figure 4 about here.]

ESTIMATION OF MIGRATION DURATION AND ANNUAL MORTALITY FOR 
To illustrate overall patterns, migration durations were determined for particles released every 15 days during the year 1961 and drifting over 23 years at fixed depth, with no mortality $(M=0)$. A histogram of the data has a log-normal shape as is usually the case for such analyses (Bodin et al. 2003; Wu \& Hu, 2007), with a clear mode around $d=13$ years 310 (=156 months) (Fig. 7a).

[Figure 5 about here.]

Figure $7 \mathrm{~b}$ shows the same histogram but reduced to 0 to 5 years migration duration. The minimum migration duration was in the class 10-11 months but does not appear in Fig. 7a since there was only one particle. The distribution changed drastically when applying a

315 mortality rate (Fig. 7c). With a mortality rate of 2 per year, the distribution of the migration duration can be estimated as in Fig. 7c. The geometric mean of this distribution was 2.4 years. An annual mortality rate equal to 2 is equivalent to a survival rate of $13.5 \%$ per year $(\exp (-2$. 1)). From the Lagrangian simulations, the distribution of the migration duration was estimated for each value of the annual mortality $M$, comprised between 0 and 10 with an incremental 320 step of 0.2 . By considering a uniform distribution on $M$, an estimation of the joint distribution $\pi_{L}(M, d)$ was obtained on a $51 \times 60$ grid. Figure 8 a shows the contour of the joint probability distribution $\pi_{L}(M, d)$. The modal value was found for a short migration duration (less than 1 year) and a high annual mortality. Figure $8 \mathrm{~b}$ shows the contour of the joint probability distribution $\pi_{E}(M, d)$ obtained from the combination of knowledge about eel ecology following Eq. 10. The maximum probability was found for migration durations close to 0.5 and annual mortality rate close to 10 . The joint probability distribution $\pi(M, d)$ was obtained from the combination of the Lagrangian probability distribution with the distribution obtained from knowledge about eel ecology (Fig. 8c). The combination of the two sources of 
information drastically reduced the uncertainty about $(d, M)$. The new distribution $\pi(M, d)$

330 had restricted values, with modal values around the point ( $d=1.5$ years; $M=4$ per year). The marginal distributions of $d$ and $M$ show that the most credible value (i.e. the geometric mean of the values) are 1.49 years for the migration duration and 3.8 per year for the mortality rate, which corresponds to a survival rate of $2.2 \%$ per year (Figs. 9a and 9b).

[Figure 6 about here.]

\section{LARVAL BEHAVIOUR DOES NOT INFLUENCE THE MIGRATION DURATION}

Migration duration and annual mortality estimates are not very sensitive to simulations of different larval behaviours. Implementing active behaviours for particles leads to sharper peaks in distributions but only small ones in geometric means (Fig. 9). The geometric mean migration duration was 1.48 years for the vertical migration experiment and 1.51 years for

340 fastest current choice (Fig. 9c and e). Comparable mean annual mortalities are 3.79 and 3.73 years respectively (Fig. 9d and f).

[Figure 7 about here.]

\section{OCEANIC CONDITIONS INFLUENCE THE MEAN MIGRATION DURATION}

Over the whole simulated years for the fixed-depth experiment, the standard deviance 345 of migration duration is 3.1 months. After removal of autocorrelation as described in Pyper \& Peterman (1998), significant negative relationships were found between the geometric mean migration duration and the large scale oceanic indices $(r=-0.51, \mathrm{p}<0.05$ with the NAO index, $\mathrm{r}=-0.51, \mathrm{p}<0.01$ with the Gulf Stream Index, and $\mathrm{r}=-0.46, \mathrm{p}<0.05$ with the 
Transport Index). The higher the oceanic indices, the lower the mean migration duration.

350 Similar results are found with the two other behaviour hypotheses.

[Figure 8 about here.]

\section{SENSITIVITY ANALYSIS TO PARAMETERS}

Elasticities of the mean migration duration and larval mortality were both low (Table II), indicating that changes in one parameter, considering the others as fixed, has a low impact on results. For instance, if $\xi$ increases by $10 \%$, the mean migration duration estimated in Exp. 1 will increase by $7 \%$. These results are consistent with Eq. 9. If the hatching rate increases, the survival rate of leptocephali decreases to maintain the steady state of the population. The same conclusion applies for the mean migration duration. If the survival rate of glass eel increases, one solution to maintain the steady state of the population is to increase the time of

360 exposure to leptocephalus mortality, as expressed by Eq. 9. The sign of elasticity is positive and therefore consistent with the steady-state hypotheses. Furthermore, given the same experiment, elasticities should have been strictly equal for parameters that have the same role in Eq. 9 , i.e. $F e c, \xi, \beta$, and $\eta$ or $M_{a}$ and $d_{a}$. The small differences stem from the numerical resimulations of these different parameters when adding a small variation.

\section{DISCUSSION}

\section{ESTIMATES OF THE MIGRATION DURATION}


To provide accurate estimates of migration duration, larval mortality has to be accounted for in Lagrangian studies. The longer that particles drift, the more particles arrive

370 to the 'finishing line'. Without accounting for mortality, the mean migration duration from the Sargasso Sea spawning area to $20^{\circ} \mathrm{W}$ ranges from 11 to 15 years. Cowen et al. (2000) and Hare et al. (2002) have similarly shown the importance of accounting for mortality in simple advection models. Taking mortality into account, the geometric mean migration duration to reach $20^{\circ} \mathrm{W}$ is about 1.5 years. The time for leptocephali to reach the continental slope and

375 metamorphose into glass eels has still to be accounted for. Glass eels may also have to wait for an increase in water temperatures before migration into estuaries can begin. These delays were not taken into account because they are highly variable and depend on local and interannual variability in water temperature.

[Table II about here.]

The duration of the migration from $20^{\circ} \mathrm{W}$ to the continental shelf was estimated as the sum of two phases, the first being the time taken to reach the continental slope where leptocephali are believed to metamorphose into glass eels. The second phase was the time lag between metamorphosis and entry to estuaries (estimated by otolith microstructure). The distance between $20^{\circ} \mathrm{W}$ and the closest coast, i.e. the coast of Ireland, is $1000 \mathrm{~km}$ and current

385 speeds in that area are about $0.2 \mathrm{~m} \mathrm{sec}^{-1}$ (Fratantoni, 2001), thus the minimum time to cover this distance is thus 58 days. This distance and duration can obviously vary greatly, resulting in differences in diffusion and time-related mortality - reflected in times of arrival (Tesch, 2003) and clines in relative levels of recruitment (e.g. Bark et al., 2007). Published estimates for the length of metamorphosis phase are about 98 days, 33-76 days and 18-52 days, 390 according to Wang \& Tzeng (1998, 2000), Lecomte-Finiger (1992) and Arai et al. (2000) 
respectively. Thus, 1 to 3 months have to be added to the migration duration to account for the metamorphosis into glass eel as well. The migration duration is therefore at least 21 months (18 months to cover the distance to $20^{\circ} \mathrm{W}$ and 3 months to cover the distance from $20^{\circ} \mathrm{W}$ to European shelves and metamorphose into glass eel).

Observations of the occurrence of leptocephali in the Sargasso Sea from February to June and main arrivals on European shelves from December to April imply that the migration duration is about 11 months or modulo 11 months (Kettle \& Haines, 2006). The 21-month migration duration proposed in this paper is consistent with this time lag between spawning and arrivals (McCleave, 2008). Results are not in agreement with otolith microstructure

400 studies and it is possible that leptocephali may have such a low metabolic rate that increments in otoliths might not be deposited daily, especially at low temperature, or may be deposited daily but are too thin to be observable in either light or scanning electronic microscopy (Bonhommeau et al., submitted).

Powles et al. (2006) demonstrated that increment formation during metamorphosis was daily in the speckled worm eel (Myrophis punctatus), but otolith growth has been observed to be strongly affected by temperature below $10^{\circ} \mathrm{C}$ in $A$. japonica glass eels by Fukuda et al. (2009). The reliability of the different methods used to estimate migration duration remains controversial. Two hypotheses are currently proposed. Otolith microstucture results estimate a short migration duration (=< 1 year, Lecomte-Finiger, 1994; Wang \& Tzeng 1998) and cohort

410 analysis, otolith macrostructure, and particle-tracking models estimate a longer migration duration (>1.5 years, Schmidt, (1922) ; van Utrecht \& Holleboom (1985), Kettle \& Haines (2006)). The present results are in agreement with longer migration duration estimates.

Passive drift of eel larvae was assumed in this work. Active migration has been suggested to explain the shorter transit times derived from otolith microstructure analyses. 
415 However, Bonhommeau et al. (accepted) estimated the swimming speed of leptocephali would need to be at least 3.4 body lengths $\sec ^{-1}$ to cross the Atlantic Ocean in six months. The swimming hypothesis also seems unlikely because of low food availability in the open-ocean and the energy cost of swimming (McCleave et al., 1998). Uncertainties about leptocephalus diet and behaviour in the wild need clarifying to improve simulation designs and

420 understanding of the oceanic phase of eels.

\section{ESTIMATES OF THE NATURAL MORTALITY ARE LOWER THAN IN OTHER FISH} SPECIES

Reliable estimates of natural mortality, especially during the early-life stages, are critical in stock assessment, recruitment forecasting and management of fish species.

425 However, estimates of natural mortality rates of fish vary widely between and within species (McGurk, 1986). For instance, the natural larval mortality of European plaice (Pleuronectes platessa), Atlantic cod (Gadus morhua) and Atlantic mackerel (Scomber scombrus) are estimated at 0.02, 0.16 and 0.69 per day respectively (Bannister et al., 1974; Ware \& Lambert, 1985; Kristiansen et al., 1997). In the present study, natural mortality of

430 leptocephali is estimated to be 3.8 per year (about 0.01 per day), lower than other fish larvae. Most fishes have a short larval stage, from a few weeks to a few months, and applying a natural mortality rate to eel larvae of the same magnitude as other pelagic larvae would make it impossible for them to effectively cross the Atlantic. This result is therefore difficult to compare to other fish species. To the authors' knowledge, no study has ever provided an

435 estimate of natural mortality of eel leptocephali for comparison with other estimates. Kettle \& Haines (2006) found that of $1.6 \times 10^{6}$ drifters released, $0.66 \%$ arrived at $25^{\circ} \mathrm{W}$ within 2 years. Actually, Kettle \& Haines (2006) tacitly induced a mortality hypothesis since their 
simulations were stopped after two complete years, i.e. equivalent to a survival rate of $100 \%$ up to two years and $0 \%$ thereafter. However, the $0.66 \%$ value is not a survival rate since no

440 realistic mortality rate was implemented in their model. The estimate of a 3.8 annual mortality rate over 21 months is equivalent to a survival rate of $0.18 \%$ larvae and is consistent with the steady-state hypothesis of the population (Eq. 7 and Fig. 3). It is also consistent with observations of glass eel arrivals. The European eel spawning season is estimated to be from February to June and mostly concentrated from March to May (Schmidt, 1922, McCleave \&

445 Kleckner, 1987, McCleave, 2008). If the natural mortality rate was very high, leptocephali that spend too much time in the Atlantic Ocean would die. This would lead to selection of individual that cross the Atlantic quickly and the migration duration would be short and the arrival dates in continental waters would form a narrow peak. This result does not correspond to observations of the seasonality of glass eel arrivals (McCleave, 2008). For instance, glass

450 eel fishing in the Bay of Biscay is generally concentrated between November and April depending on the distance from the edge of the continental shelf. However, catches from illegal fishing done outside the fishing season provide a substantial amount of glass eel even during July and August. For these latecomer leptocephali, it implies a more prolonged sojourn in the Atlantic Ocean as well as a longer migration that would not be possible if the mortality 455 rate was very high.

As a result, a higher mortality rate during larval stage than during next stages has been found which is consistent with general considerations about the importance of this specific period (e.g. Levin \& Stunz, 2005).

BEHAVIOUR HYPOTHESES HAVE A WEAK IMPACT ON MEAN MIGRATION 
Mean migration duration and annual mortality do not seem to be greatly influenced by the behaviours simulated. However, the distributions of migration durations have more pronounced modes for the experiments with vertical diurnal migration and faster current choice (Fig. 9). This actually could be an artefact induced by the Lagrangian simulations. For these two experiments, fewer particles were released than for the fixed-depth experiment. In the fixed-depth experiment, particles were released at each vertical mesh level (26 levels), but this was not necessary for simulations involving the two other behaviour hypotheses. For instance, regarding the fastest current choice behaviour, all particles starting at the same horizontal position would have chosen the same depth levels at the first time step and so on.

470 The same applies to the vertical diurnal migration since depths are fixed at $300 \mathrm{~m}$ during the day and 50m at night. Consequently, once the first particle has arrived, some time-classes have a low number of particles or none at all for these two behaviour experiments. When applying a mortality rate, the first particle was selected and had a high probability in the joint distribution of $M$ and $d$ but the next particles had very low or null probability. When

475 multiplying the two joint distributions, i.e. Lagrangian results $\left(\pi_{L}(M, d)\right.$; Fig. 8a) and steady-state hypothesis $\left(\pi_{E}(M, d)\right.$; Fig. $\left.8 \mathrm{~b}\right)$, the joint probability $(\pi(M, d))$ of the first particle was therefore high compared to the other. This helps explain the pronounced mode for experiments with vertical migration and the fastest current choice. Nevertheless, the range of values between the different experiments is similar and suggests that the behaviours 480 modelled do not significantly minimise migration duration. Vertical diurnal migration is probably a way to avoid predation and optimise foraging, as is the case for other zooplankton (Steinberg et al., 2002), rather than a strategy to accelerate larval drift.

\section{INFLUENCE OF OCEANIC FEATURES ON EUROPEAN EEL RECRUITMENT}


The negative correlations detected between the mean migration duration and oceanic predictable, since when these indices are high, mid-latitude westerly winds are intensified over the North Atlantic and currents are faster. For example, when the NAO is high, a larger number of particles will successfully cross the Atlantic, because the migration duration is shorter and hence mortality is lower. However, all these indices were relatively low before the 490 1980s and increased steadily until the mid-1990s. The period 1980-1995, when oceanic conditions were apparently more favourable regarding the migration duration and hence survival, was paradoxically the period when the decline in eel recruitment began. Three nonexclusive hypotheses may explain this apparent anomaly: either the high indices are also related to strong mesoscale eddies that may trap particles, but are not resolved in the ocean

495 general circulation model used, or the physical oceanic conditions such as current speeds may not affect the recruitment success. The latter means that the negative relationships found between NAO and eel recruitment indices (Knights, 2003; Friedland et al., 2007) do not correspond to the signal of physical oceanic conditions described by the NAO. The NAO is indeed an integrative index and is related to a large number of physical but also biological

500 features (Hurrell, 1995; Fromentin \& Planque, 1996; Straile \& Stenseth, 2007). As the NAO is negatively correlated to primary production in the Sargasso Sea (Bates, 2001), the negative relationship between NAO and recruitment could be linked to biological production in the eel spawning area as showed by Bonhommeau et al. (2008). Ocean general circulation models that resolve mesoscale and sub-mesoscale eddies could be used to determine whether the 505 same patterns of migration durations can be found and whether the ocean circulation has a direct impact on eel leptocephali survival. The use of high resolution models has been initiated for the Japanese eel (Kimura et al.; 1994; Kim et al., 2007). A third hypothesis is 
that anthropogenic adverse effects started seriously interfering with eel recruitment in the early 1980s, regardless of oceanic conditions.

With regards to steady-state hypotheses, Eq. 7 describes the necessary conditions for a species to maintain its population. This equation applies when the parameters used are those of the population at steady-state. However, cyclic fluctuations in levels of recruitment and stocks have been observed and make it difficult to determine what a steady state is. To overcome this problem, parameters given in the literature when the population was fluctuating

515 around a mean and showing no clear trends have been favoured (before the decline in the 1980s).

Regarding the current decline of European eel, Eq. 7 is clearly false since one female does not produce two individuals able to spawn (see depletion rate estimated by Åström \& Dekker, 2007). However, this study aimed at estimating the natural mortality and migration duration of leptocephali. The assumption was made that natural mortality and migration duration are not influenced by factors affecting the European eel during its continental life stages such as overfishing, pollution, habitat loss, etc. This assumption is also conceptually false since, for instance, fishing may select glass eels arriving in European rivers before or after the fishing season. Thus, individuals that have a shorter or longer migration duration may be genetically

525 favoured. However, the authors consider that it is currently impossible to assess the evolutionary effects of fishing, pollution, etc. on eel larval migration. This assumption (based on and extending Eq. 9) can be written as:

$$
e^{-M \cdot t} \approx \frac{2}{F e c \cdot \xi \cdot \beta \cdot e^{-M_{a} \cdot d_{a}} \cdot \eta} \approx \frac{X}{F e c \cdot \xi \cdot \beta \cdot e^{-M_{a} \cdot d_{a}} \cdot \eta \cdot \prod_{i} \delta_{i}}
$$

where $X$ is the current number of spawners produced by a female, $\delta_{i}$ are all other survival rates induced by the impact of overfishing, habitat loss, pollution, climate, etc. on the eel. It 
was thus assumed that factors inducing the current decline in eel population have no effect on migration and larval mortality. When using only Lagrangian simulations where the eel population was assumed to be at steady-state (i.e. before the decline in the 1980s), the same mean migration duration and mortality was obtained (data not shown). This reinforces the idea that using a steady-state hypothesis is an appropriate first assumption to estimate the mean migration duration and larval mortality. The last hypothesis that has been made when assuming that one female produces two individuals able to spawn is that the sex ratio is $1: 1$. This hypothesis may be wrong but currently there is no way of estimating the overall sex ratio of the European eel throughout the species range.

In conclusion, Lagrangian simulations coupled with mortality hypotheses have allowed the estimation of the trans-Atlantic migration duration and the natural mortality of European eel leptocephali. Results show the importance of accounting for mortality in Lagrangian modelling of the duration of fish larval migrations. In particular, with a mortality hypothesis a strong influence of the departure month is revealed. It could be hypothesized that

545 a temporal determinism of the spawning season stems from physical oceanography. The European eel population can maximize larval migration success (i.e. minimize the migration duration) when spawning from March to June, due to favourable currents over this period (Fig. 6). The mean migration duration is estimated at 21 months, longer than estimates derived from otolithometry, but shorter than those from cohort and other analyses. Estimated

550 larval mortality is low compared to other fish species, i.e. an annual mortality rate of 3.8 (equivalent to a survival rate of $0.12 \%$ over the migration). Allowing for different leptocephalus behaviours did not appear to have an influence on simulated mean migration duration and mortality. Environmental indices indicative of changes in transport currents do not seem to be related to the post-1980s decline in glass eel recruitment, since they appeared 
555 to be more favourable (lower migration duration) when recruitment declined. These results may be influenced by the resolution of the ocean model in use and improvements have to be considered in future work. Lagrangian simulations appear to be a promising way to understand the migrations and early life history of eels and the use of higher resolution ocean general circulation models will help. The implementation of a decreasing mortality rate of

560 larvae with time and growth in size could be a further improvement as the mortality rate of fish larvae is known to decrease with increasing size (Cushing, 1974; Pearcy, 1984). The online coupling of Lagrangian simulations and mortality of larvae would also be informative.

These results fit with the unique developmental strategy of eel larvae to achieve their migration over long distances in open-oceans of low productivity. The ability of eel to adapt

565 to different environmental conditions, i.e. its plasticity, allows it to colonize a wide-spectrum of habitat from the Arctic polar circle to the shelves of Morocco. Moreover, the low mortality of leptocephali in the open ocean, demonstrated in the present work, allows them to survive major variations in oceanic circulation. Nevertheless, high amplitude and very long-term variations of oceanic circulation have had a strong impact. The Wisconsin (20000 BP) or

570 Younger Drias (12000 BP) glaciations have resulted in a strong reduction of the speed of the Gulf Stream (Lehman \& Keigwin, 1992; Keigwin \& Jones, 1994; Duplessy, 1999; LynchStieglitz et al., 1999; Rahmstorf, 2002). In turn, this decrease in the speed of the Gulf Stream may have initiated declines in eel recruitment (Wirth \& Bernatchez, 2003) and a concentration in restricted areas (Kettle et al. 2008b). Eels appear indeed to have maintained a

575 continuous presence in southern Europe throughout the last glacial period while they were absent from northwestern Europe north of the Gironde drainage basin (Kettle et al. 2008b). Regarding the current decline in eel recruitment, one of the major questions is the potential effects of global warming and its consequences on global circulation. If eels adopt the strategy 
of restricting themselves to specific areas depending on ocean circulation (e.g. in the

580 Mediterranean and the Atlantic coast of western Europe, as during glaciation events), this may have strong implications in terms of management. In particular, this raises questions about the future benefits of stocking in the northern part of the species distribution.

\section{ACKNOWLEDGMENTS}

The authors thank Jean-Marc Molines (CNRS, LEGI, Grenoble) who provided the Drakkar

585 model simulation. The Drakkar model has been run at the IDRIS computing centre of CNRS, Orsay, France. SB thanks S. \& S. Mazué for their fruitful discussions. We thank two anonymous referees for their in-depth review and helpful comments. We also thank Brian Knights for his considerable efforts for this special issue and his helpful comments and discussions. 
Arai, T., Otake, T. \& Tsukamoto, K. (2000). Timing of metamorphosis and larval segregation of the Atlantic eels Anguilla rostrata and A. anguilla, as revealed by otolith microstructure and microchemistry. Marine Biology 137, 39-45.

595 Åström, M. \& Dekker, W. (2007). When will the eel recover? A full life-cycle model. ICES Journal of Marine Science 64, 1491-1498.

Blanke, B. \& Raynaud, S. (1997) Kinematics of the Pacific Equatorial Undercurrent: a Eulerian and Lagrangian approach from GCM results. Journal of Physical Oceanography 27,1038-1053.

600 Blanke, B., Arhan, M., Madec, G. \& Roche, S. (1999) Warm water paths in the equatorial Atlantic as diagnosed with general circulation model. Journal of Physical Oceanography 29,2753-2768.

Blanke, B., Speich, S., Madec, G. \& Döös, K. (2001) A global diagnostic of interocean mass transfers. Journal of Physical Oceanography 31,1623-1632.

Bannister, R.C.A., Harding, D. \& Lockwood, S.J. (1974). Larval mortality and subsequent year class strength in the plaice (Pleuronectes platessa L.). In The early life history of fish (Blaxter, J.H.S., ed.), pp. 21-37. Springer-Verlag, Berlin.

Bark, T., Knights, B., Kirkwood, G., El-Hosaini, H. \& Williams, B. (2007). The development and implementation of biological reference points for the management of the European eel. Tech. rept. SF0236. Defra R\&D.

Barnier, B., Madec, G., Penduff, T., Molines, J.M., Tréguier, A.-M., Le Sommer, J., Beckmann, A., Biastoch, A., Boening, C., Dengg, J., Derval, C., Durand, E., Gulev, S., Remy, E., Talandier, C., Theetten, S., Maltrud, M., McClean, J. \& DeCuevas, B. (2006). Impact of partial steps and momentum advection schemes in a the global ocean circulation model at eddy permitting resolution. Ocean Dynamics 56, 543-567.

Bates, N.R. (2001). Interannual variability of oceanic $\mathrm{CO}_{2}$ and biogeochemical properties in the Western North Atlantic subtropical gyre. Deep-Sea Research Part II-Topical Studies in Oceanography 48,1507-1528.

Beaugrand, G. \& Reid, P.C. (2003). Long-term changes in phytoplankton, zooplankton and salmon related to climate. Global Change Biology 9, 801-817.

Berg, R. \& Jorgensen, J. (1994). Stocking experiment with 0+ eels (Anguilla anguilla L.) in Danish streams: post stocking movements, densities and mortality. In Rehabilitation of freshwater fisheries (Cowx, I. G., ed.), pp. 314-325. Oxford: Fishing News Books.

Bertin, L. (1956). Eels, a biological study. Cleaver-Hume Press Ltd, London.

625 Bodin, J., Porel, G. \& Delay, F. (2003). Simulation of solute transport in discrete fracture networks using time domain random walk method. Earth and Planetary Science Letters 208, 297-304.

Boëtius, I. \& Boëtius, J. (1980) Experimental maturation of female silver eels, Anguilla anguilla. Estimates of fecundity and energy reserves for migration and spawning. Dana $630 \quad$ 1,1-28.

Bolliet, V., Lambert, P., Rives, J. \& Bardonnet, A. (2007). Rhythmic swimming activity in Anguilla anguilla glass eels: Synchronisation to water current reversal under laboratory conditions. Journal of Experimental Marine Biology and Ecology 344,54-66. 
Bonhommeau, S., Chassot, E. \& Rivot, E. (2008). Fluctuations in European eel (Anguilla anguilla) recruitment resulting from environmental changes in the Sargasso Sea. Fisheries Oceanography 17, 32-44.

Bonhommeau, S., Blanke, B., Tréguier, A.-M., Grima, N., Rivot E., Vermard, Y. \& Le Pape, O. (accepted). Can the European eel larvae cross the Atlantic Ocean in 6 months? Fisheries Oceanography.

Bonhommeau, S., Castonguay, M., Rivot, E., Le Pape, O. \& Sabatié, R. (submitted). The controversy around the migration duration of Atlantic Anguilla larvae. Fish and Fisheries.

Castonguay, M. \& McCleave, J.D. (1987). Vertical distributions, diel and ontogenic vertical migrations and net avoidance of leptocephali of Anguilla and other common species in the Sargasso Sea. Journal of Plankton Research 9: 195-214.

Cowen, R.K., Lwiza, K.M.M., Sponaugle, S., Paris, C.B. \& Olson, D.B. (2000). Connectivity of marine populations: Open or closed? Science 287, 857-859.

Curry, R.G. \& McCartney, M.S. (2001). Ocean gyre circulation changes associated with the North Atlantic Oscillation. Journal of Physical Oceanography 31, 3374-3400.

Cushing, D.H. (1974). The possible density-dependence of larval mortality and adult mortality in fishes. In The early life history of fishes (Blaxter, J.H.S., ed.), pp. 103-101. Springer-Verlag, New York, NY.

Dekker, W. (2000). A Procrustean assessment of the European eel stock. ICES Journal of Marine Science 57, 938-947.

655 Duplessy, J. C. (1999). Oceanography - Climate and the Gulf Stream. Nature 402, 593-595.

Fratantoni, D. M. (2001). North Atlantic surface circulation during the 1990's observed with satellite-tracked drifters. Journal of Geophysical Research-Oceans 106(C10), 2206722093.

Friedland, K.D., Miller, M.J. \& Knights, B. (2007). Oceanic changes in the Sargasso Sea and declines in recruitment of the European eel. ICES Journal of Marine Science 64, 519530.

Fromentin, J.-M. \& Planque, B. (1996). Calanus and environment in the eastern North Atlantic II. Influence of the North Atlantic Oscillation on $C$. finmarchicus and $C$. helgolandicus. Marine Ecology-Progress Series 134, 111-118.

665 Fukuda, N., Kuroki, M., Shinoda, A., Yamada, Y., Okamura, A. \& Tsukamoto, K. (2009) Influence of water temperature and feeding on otolith growth in Anguilla japonica glass eels and elvers: Does otolith growth cease at low temperature? Journal of Fish Biology (this volume).

Furuita, H., Ohta, H., Unuma, T., Tanaka, H., Kagawa, H., Suzuki, N. \& Yamamoto, T. (2003). Biochemical composition of eggs in relation to egg quality in the Japanese eel, Anguilla japonica. Fish Physiology and Biochemistry 29,37-46.

Gascuel, D. (1986) Flow-carried and active swimming migration of the glass eel (Anguilla anguilla) in the tidal area of a small estuary on the French Atlantic coast. Helgoländer Meeresuntersuchungen 40, 321-326.

675 Hare, J.A., Churchill, J.H., Cowen, R.K., Berger, T.J., Cornillon, P.C., Dragos, P., Glenn, S. M., Govoni, J.J. \& Lee, T.N. (2002). Routes and rates of larval fish transport from the southeast to the northeast United States continental shelf. Limnology and Oceanography 47, 1774-1789.

Hjort, J. (1914). Fluctuations in the great fisheries of Northern Europe. Rapport des Procèsverbaux du Conseil international pour l'Exploration de la Mer 20, 1-228. 
Hurrell, J. W. (1995). Decadal trends in the North-Atlantic Oscillation - Regional temperatures and precipitation. Science 269, 676-679.

Jung, S., Hwang, S.-D. \& Kim, J. (2008). Fecundity and growth-dependent mortality of Pacific anchovy (Engraulis japonicus) in Korean coastal waters. Fisheries Research 93, 39-46.

Keigwin, L.D. \& Jones, G.A. (1994). Western North-Atlantic evidence for millennial-scale changes in Ocean circulation and climate. Journal of Geophysical Research-Oceans 99(C6), 12397-12410.

Kettle, A. J. \& Haines, K. (2006). How does the European eel (Anguilla anguilla) retain its population structure during its larval migration across the North Atlantic Ocean? Canadian Journal of Fisheries and Aquatic Sciences 63, 90-106.

Kettle, A.J., Bakker, D.C.E. \& Haines, K. (2008a). Impact of the North Atlantic Oscillation on the trans-Atlantic migrations of the European eel (Anguilla anguilla). Journal of Geophysical Research Ocean 113, doi:10.1029/2007 JG000589.

695 Kettle, A.J., Heinrich, D., Barrett, J.H., Benecke, N. \& Locker, A. (2008b) Past distributions of the European freshwater eel from archaeological and palaeontological evidence. Quaternary Science Reviews 27, 1309-1334.

Kim, H., Kimura, S., Shinoda, A., Kitagawa, T., Sasai, Y. \& Sasaki, H. (2007) Effect of El Niño on migration and larval transport of the Japanese eel (Anguilla japonica). ICES Journal of Marine Science 64, 1387-1395.

Kimura, S., Döös, K. \& Coward, A.C. (1999). Numerical simulation to resolve the issue of downstream migration of the Japanese eel. Marine Ecology Progress Series 186, 303306.

Knights, B. (2003). A review of the possible impacts of long-term oceanic and climate changes and fishing mortality on recruitment of anguillid eels of the Northern Hemisphere. Science of the Total Environment 310, 237-244.

Kristiansen, T.S., Jorstad, K.E., Ottera, H., Paulsen, O.I. \& Svasand, T. (1997). Estimates of larval survival of cod by releases of genetically marked yolk-sac larvae. Journal of Fish Biology 51, 264-283.

710 Lecomte-Finiger, R. (1992). Growth history and age at recruitment of European glass eels (Anguilla anguilla) as revealed by otolith microstructure. Marine Biology 114, 205-210.

Lehman, S.J., and Keigwin, L.D. (1992). Sudden changes in North-Atlantic circulation during the last deglaciation. Nature 356, 757-762.

Lehodey, P., Alheit, J., Barange, M., Baumgartner, T., Beaugrand, G., Drinkwater, K., Fromentin, J.-M, Hare, S.H., Ottersen G., Perry, R.I., Roy, C., van der Lingen, C.D. \& Wernerl, F. (2006). Climate Variability, Fish, and Fisheries. Journal of Climate 19, 5009-5030.

Levin, P.S. \& Stunz, G.W. (2005). Habitat triage for exploited fishes: can we identify essential fish habitat? Estuarine Coastal and Shelf Science 64, 70-78.

Lynch-Stieglitz, J., Curry, W. B. \& Slowey, N. (1999). Weaker Gulf Stream in the Florida straits during the last glacial maximum. Nature 402, 644-648.

Madec, G., Delecluse, P., Imbard, M. \& Levy, C. (1998). OPA 8.1 general circulation model reference manual. Notes de l'IPSL 11. Université P. et M. Curie, Paris, France.

McCleave, J. D. (2008). Contrasts between spawning times of Anguilla species estimated from larval sampling at sea and from otolith analysis of recruiting glass eels. Marine Biology 155, 249-262. 
McCleave, J.D. \& Kleckner, R.C. (1987). Distribution of leptocephali of the catadromous Anguilla species in the Western Sargasso Sea in relation to water circulation and migration. Bulletin of Marine Science 41, 789-806.

McCleave, J.D., Kleckner, R.C. \& Castonguay, M. (1987) Reproductive sympatry of American and European eels and implications for migration and taxonomy. American Fisheries Society Symposium 1, 286-297.

McCleave, J.D., Brickley, P.J., O'Brien, K.M., Kistner, D.A., Wong, M.W., Gallagher, M. \& Watson, S.M. (1998). Do leptocephali of the European eel swim to reach continental waters? Status of the question. Journal of the Marine Biological Association of the United Kingdom 78, 285-306.

McGurk, M.D. (1986). Natural mortality of marine pelagic fish eggs and larvae: role of spatial patchiness. Marine Ecology-Progress Series 34, 227-242.

Moriarty, C. \& Dekker, W. (Eds). (1997). Management of the European eel. Fisheries Bulletin, The Marine Institute, Dublin, Ireland, 15, pp. 110.

Pearcy, W.G. (1984). Ecology of an estuarine population of winter flounder, Pseudopleuronectes americanus (Walbaum). Part 1-4. Bulletin of the Bingham Oceanographic Collection, Yale University, 18-78.

Peterson, I. \& Wroblewski, J.S. (1984). Mortality rate of fishes in the pelagic ecosystem. Canadian Journal of Fisheries and Aquatic Sciences 41, 1117-1120.

Powles, P.M., Hare, J.A., Laban, E.H. \& Warlen, S.M. (2006) Does eel metamorphosis cause a breakdown in the tenets of otolith applications? A case study using the speckled worm eel (Myrophis punctatus, Ophichtidae). Canadian Journal of Fisheries and Aquatic Sciences 63, 1460-1468.

750 Pyper, B.J. \& Peterman, R.M. (1998). Comparison of methods to account for autocorrelation in correlation analyses of fish data. Canadian Journal of Fisheries and Aquatic Sciences 55, 2127-2140.

Rahmstorf, S. (2002). Ocean circulation and climate during the past 120,000 years. Nature 419, 207-214.

Schmidt, J. (1922). The breeding places of the eels. Philosophical Transactions of the Royal Society of London, Series B 211, 179-208.

Schmidt, J. (1923). Breeding places and migrations of the Eel. Nature 111, 51-54.

Steinberg, D. K., Goldthwait, S. A. \& Hansell, D. A. (2002). Zooplankton vertical migration and the active transport of dissolved organic and inorganic nitrogen in the Sargasso Sea. Deep-Sea Research Part I-Oceanographic Research Papers 49, 1445-1461.

Straile, D. \& Stenseth, N. C. (2007). The North Atlantic Oscillation and ecology: links between historical time-series, and lessons regarding future climate warming. Climate Research 34,: 259-262.

Taylor, A.H. \& Stephens, J.A. (1998). The North Atlantic oscillation and the latitude of the Gulf Stream. Tellus Series A-Dynamic Meteorology and Oceanography 50, 134-142.

Tesch, F.-W. (2003). The eel. $3^{\text {rd }}$ edn. Blackwell Publishing, London.

Tréguier, A.-M., Theetten, S., Chassignet, E., Penduff, T., Smith, R., Talley, L., Beismann, J.O. \& Böning, C. (2005). The North Atlantic subpolar gyre in four high-resolution models. Journal of Physical Oceanography 35, 757-774.

770 Unuma, T., Kondo, S., Tanaka, H., Kagawa, H., Nomura, K. \& Ohta, H. (2004). Determination of the rates of fertilization, hatching and larval survival in the Japanese eel, Anguilla japonica, using tissue culture microplates. Aquaculture 241, 345-356. 
van Utrecht, W.L. \& Holleboom, M.A. (1985). Notes on eel larvae (Anguilla anguilla Linneaeus, 1758) from the central and eastern north Atlantic and on glass eels from European continental shelf. Bijdragen tot de Dierkunde 55, 249-262.

Wang, C.H. \& Tzeng, W.N. (1998). Interpretation of geographic variation in size of American eel Anguilla rostrata elvers on the Atlantic coast of North America using their life history and otolith ageing. Marine Ecology-Progress Series 168, 35-43.

Wang, C.H. \& Tzeng, W.N. (2000). The timing of metamorphosis and growth rates of American and European eel leptocephali: A mechanism of larval segregative migration. Fisheries Research 46, 191-205.

Ware, D.M. \& Lambert, T.C. (1985). Early life history of Atlantic mackerel (Scomber scombrus) in the southern Gulf of St. Lawrence. Canadian Journal of Fisheries and Aquatic Sciences 42, 577-592.

785 Wirth, T. \& Bernatchez, L. (2003). Decline of North Atlantic eels: a fatal synergy ? Proceedings of the Royal Society of London Series B-Biological Sciences 270, 681-688.

$\mathrm{Wu}$, J. \& Hu, B. X. (2007). Numerical method of moments for solute transport in a nonstationary flow field conditioned on hydraulic conductivity and head measurements. Stochastic Environmental Research and Risk Assessment 21, 665-682. 


\section{List of Figures}

Figure 1 Map of the initial positions for the Lagrangian simulations using the Drakkar model (i.e. each $1 / 4^{\circ}$ ) and the location of the European eel spawning area (polygon; redrawn from McCleave et al., 1987). The upper right panel shows $20^{\circ} \mathrm{W}$ migration 'finishing line' in the Atlantic Ocean.

795 Figure 2 Probability distribution of the different parameters used to calculate the survival rate of leptocephalus.

Figure 3 Probability distribution of leptocephali survival rate accounting for uncertainties in the values for different parameters in Eq. 7 gathered from the literature.

Figure 4. Proportion of particles successfully crossing $20^{\circ} \mathrm{W}$ meridian at different latitudes.

800 Particles were released over 5 years within the eel spawning area and simulations allowed for vertical diurnal migration. The map on the right hand side shows the location of the latitude bins defining the histogram and is drawn up to $20^{\circ} \mathrm{W}$ where particles were counted.

Figure 5: Trajectories of all the particles released in the eel spawning area and successfully crossing $20^{\circ} \mathrm{W}$ meridian. Particles were tracked over 5 years and undergo a vertical diurnal migration from $50 \mathrm{~m}$ at night to $300 \mathrm{~m}$ during the day. Colour scale represents the density (number of particles that entered a box) in each bin defined as a $1^{\circ}$ longitude $\mathrm{x} 1^{\circ}$ latitude box. $n$ is the number of particles that reached $20^{\circ} \mathrm{W}$ within the period defined in the panel title.

Figure 6: Proportion of particles released in the eel spawning area that reached $20^{\circ} \mathrm{W}$ for each

810 departure month (from January (1) to December (12)). Particles were tracked over 5 years and undergo a vertical diurnal migration from $300 \mathrm{~m}$ during the day to $50 \mathrm{~m}$ at night. Solid line represents the proportion without applying a mortality hypothesis and dashed line, applying an annual mortality rate (3.8) hypothesis. The black rectangle is the estimated spawning season for the European eel (McCleave, 2008).

815 Figure 7. (a) Histogram of the time needed to reach $20^{\circ} \mathrm{W}$ for particles released in the Sargasso Sea every 15 days during the year 1961 and drifting for a maximum of 23 years. Each bar represents the percentage of all particles reaching $20^{\circ} \mathrm{W}$ over different time classes (b) The same histogram truncated at 5 years. (c) Plot of the same histogram when applying an annual mortality $(\mathrm{M})$ of 2 . Figures used results of the fixed-depth experiment.

820 Figure 8. (a) Probability distribution of the migration durations estimated by Lagrangian simulations for different annual mortalities (denoted $\pi_{L}(M, d)$ in the text). This figure shows the results of experiments at fixed-depth. (b) Probability distribution of migration durations estimated by the steady state hypothesis of the population (see Eq. 10) for different annual mortalities (denoted $\pi_{E}(M, d)$ in the text). (c) Intersection of the probability

825 distribution of migration durations estimated by the steady state hypothesis of the population and by the Lagrangian simulations (denoted $\pi(M, d)$ in the text)

Figure 9. Marginal distributions of the migration duration estimated using Eq. 10 for (a) the fixed depth experiments, (c) the vertical migration experiments, (e) and the faster current 
choice experiments, (b) the annual mortality estimated using Eq. 10 for the fixed depth 830 experiments, (d) the vertical migration experiments and (f) and the faster current choice experiments. 


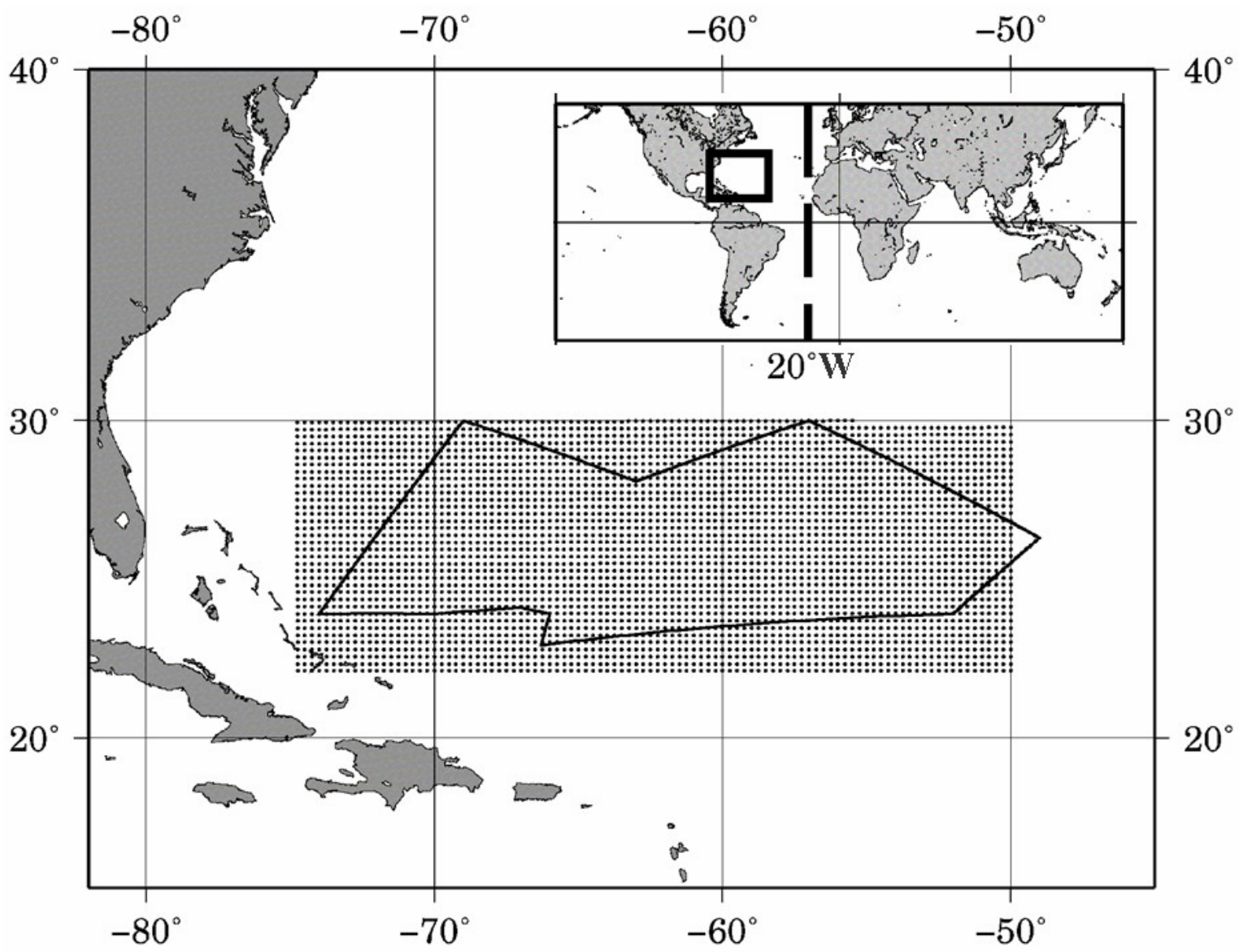

Figure 1: Map of the initial positions for the Lagrangian simulations using the Drakkar model (i.e. each $1 / 4^{\circ}$ ) and the location of the European eel spawning area (polygon; redrawn from 835 McCleave et al., 1987). The upper right panel shows the $20^{\circ} \mathrm{W}$ migration 'finishing line' in the Atlantic Ocean. 

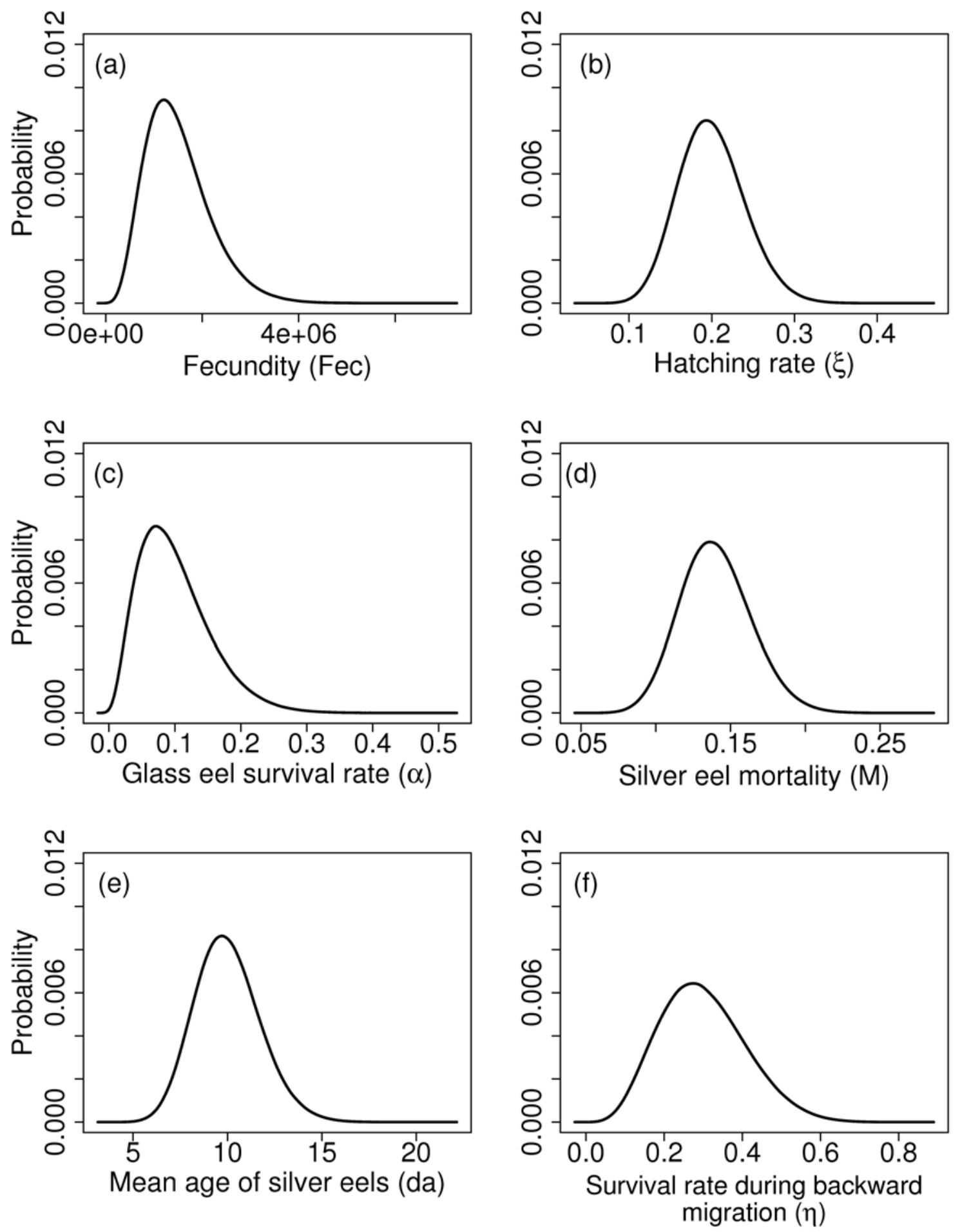

Figure 2: Probability distribution of the different parameters used to calculate the survival rate of leptocephali. 


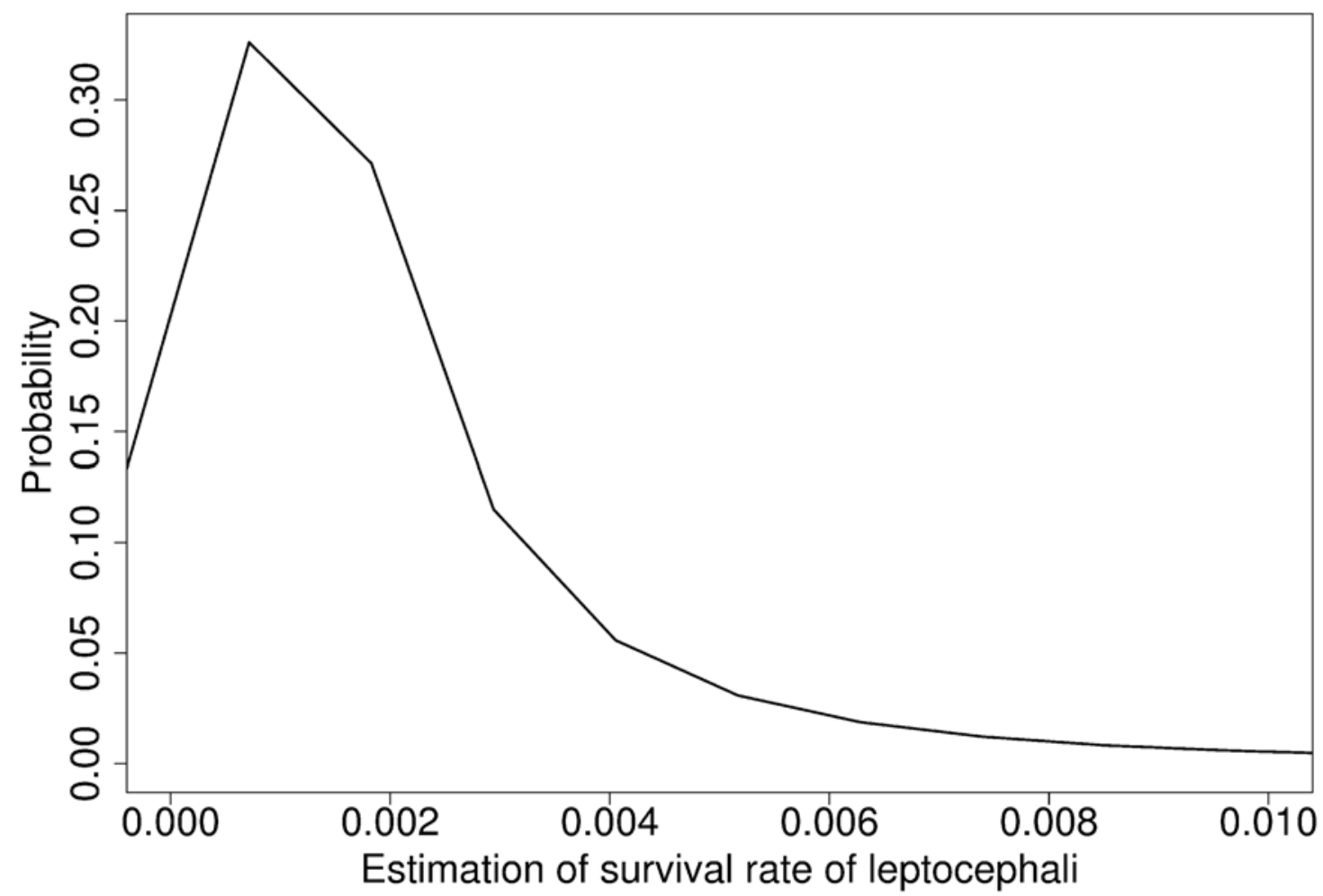

igure 3: Probability distribution of leptocephali survival rate accounting for uncertainties in the values for different parameters in Eq. 7 gathered from the literature. 

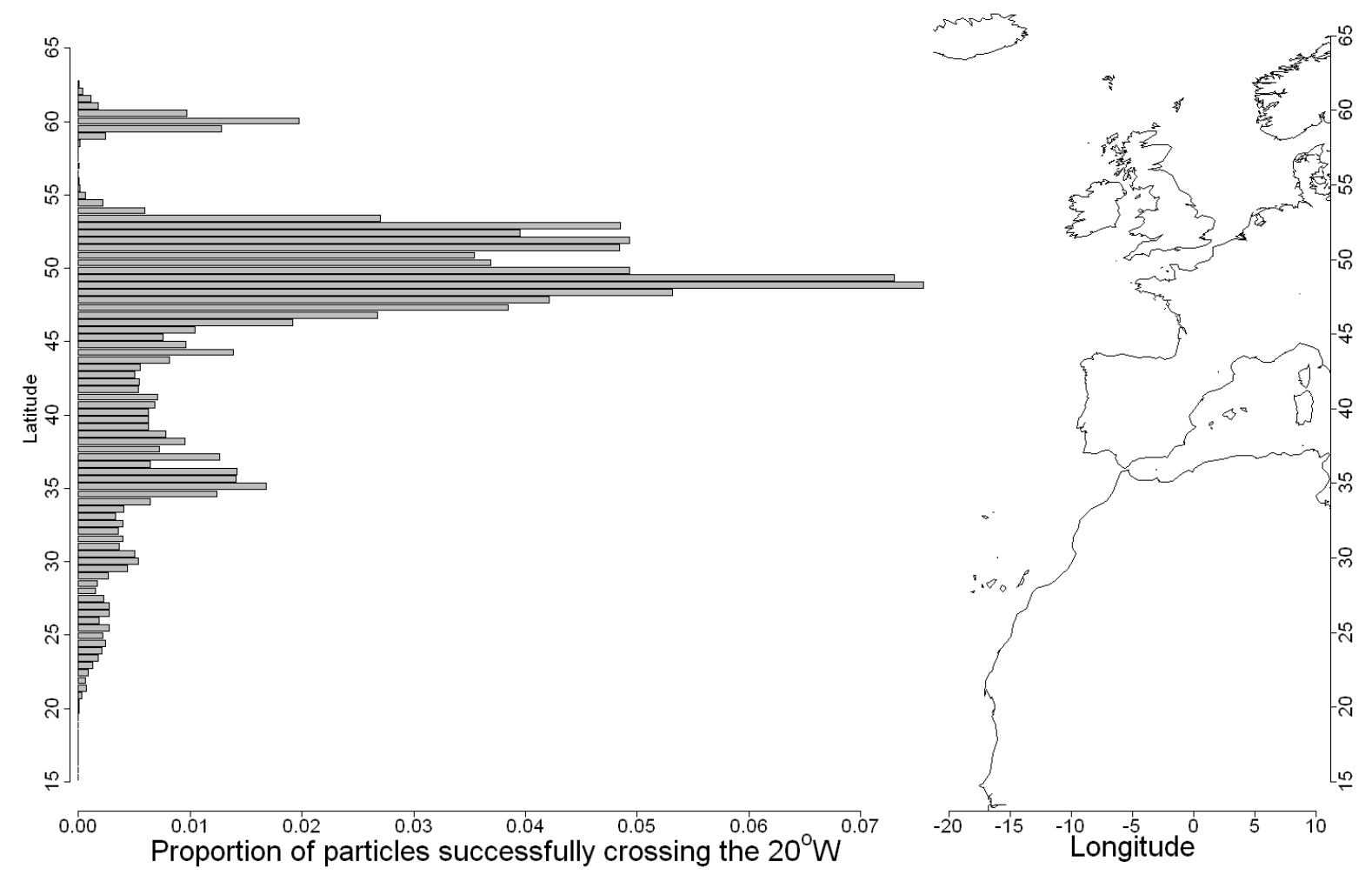

Figure 4: Proportion of particles successfully crossing the $20^{\circ} \mathrm{W}$ meridian at different 845 latitudes. Particles were released over 5 years within the eel spawning area and simulations allowed for vertical diurnal migration. The map on the right hand side shows the location of the latitude bins defining the histogram and is drawn up to the $20^{\circ} \mathrm{W}$ where particles were counted. 

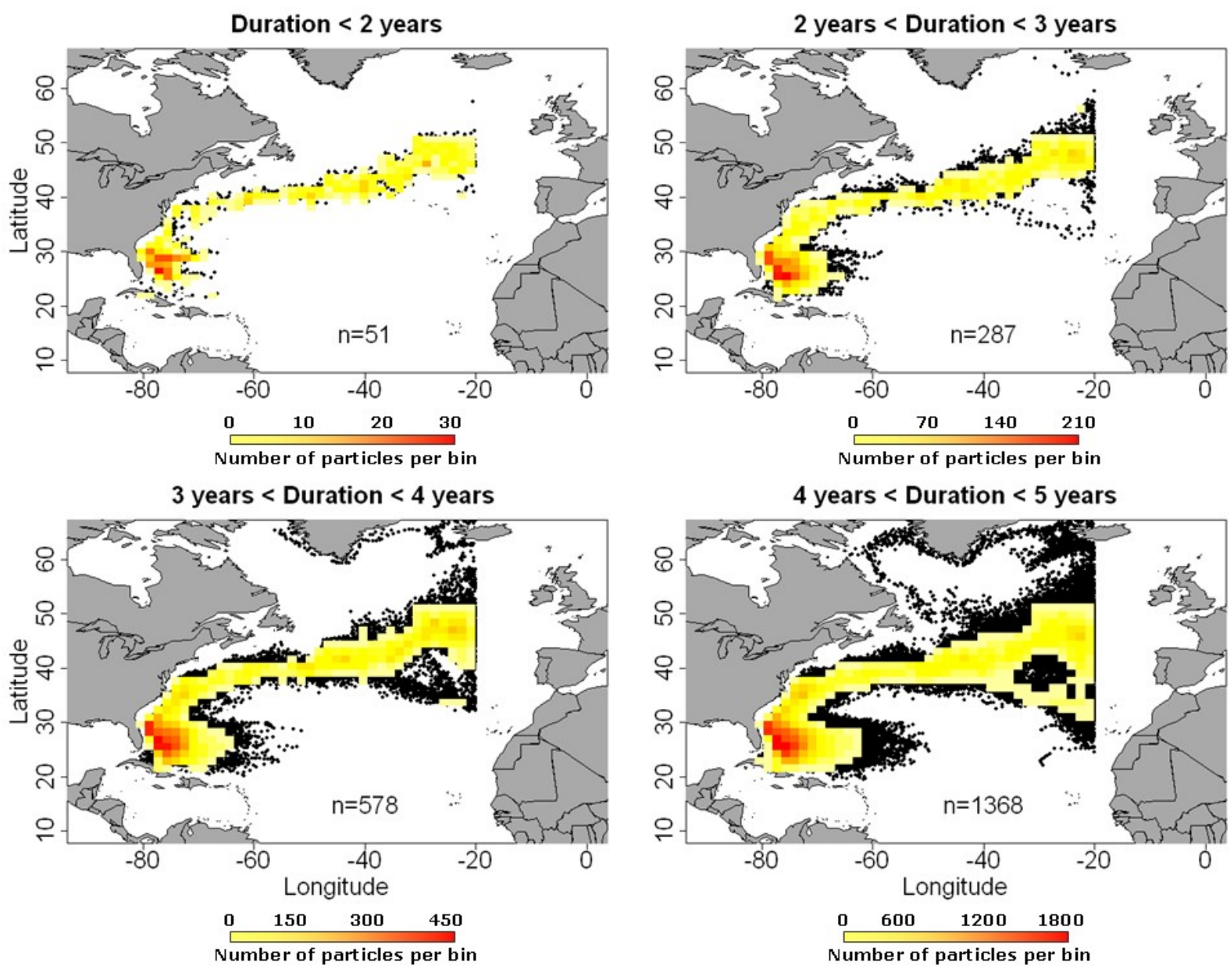

850 Figure 5: Trajectories of all the particles released in the eel spawning area and successfully crossing the $20^{\circ} \mathrm{W}$ meridian. Particles were tracked over 5 years and undergo a vertical diurnal migration from $50 \mathrm{~m}$ at night to $300 \mathrm{~m}$ during the day. Colour scale represents the density (number of particles that entered a box) in each bin defined as a $1^{\circ}$ longitude $\mathrm{x} 1^{\circ}$ latitude box. $n$ is the number of particles that succeeded to reach the $20^{\circ} \mathrm{W}$ over the period defined in panel title. 


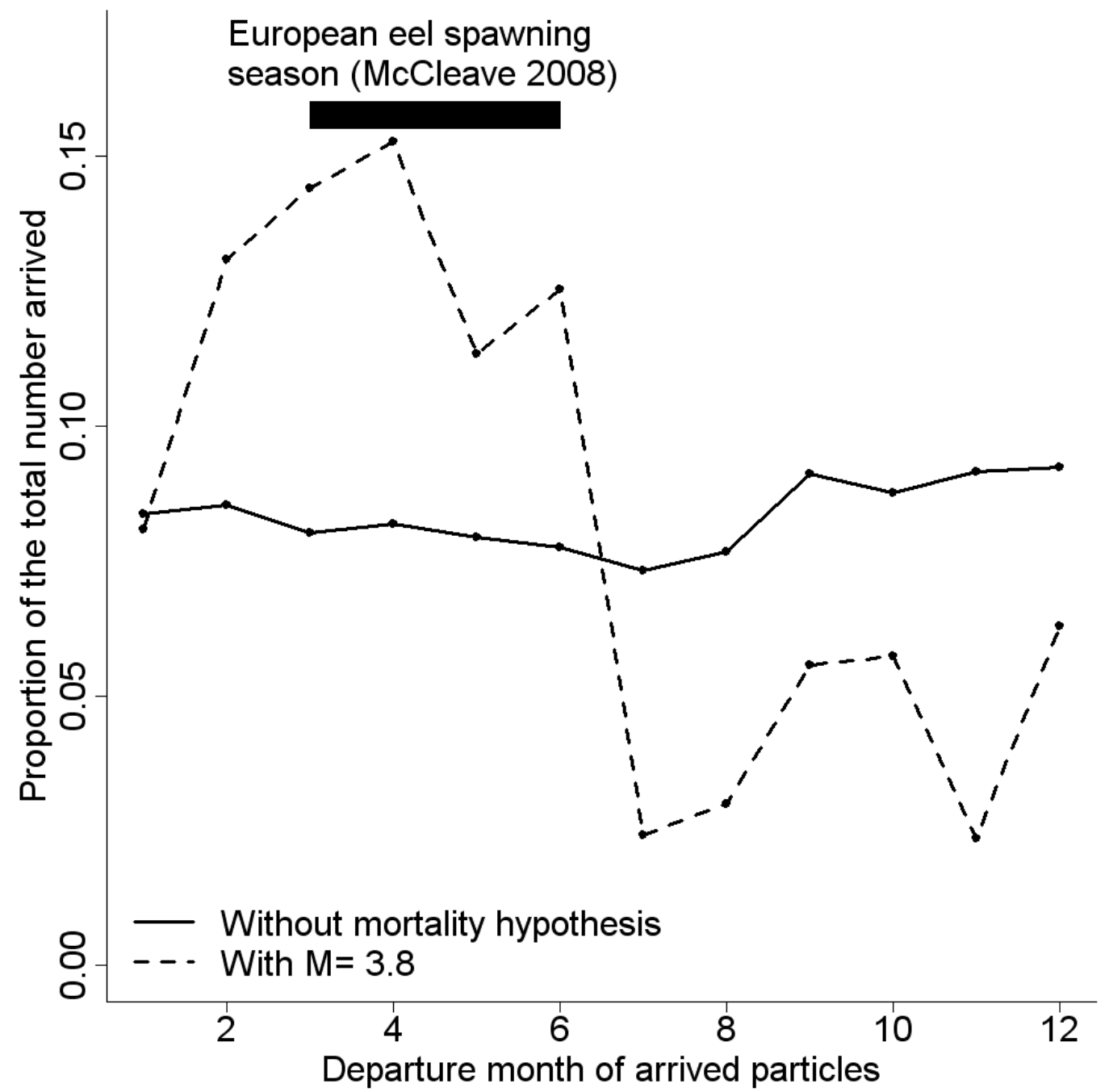

Figure 6: Proportion of particle released in the eel spawning area and that reached the $20^{\circ} \mathrm{W}$ for each departure month (from January (1) to December (12)). Particles were tracked over 5 years and undergo a vertical diurnal migration from $300 \mathrm{~m}$ at night to $50 \mathrm{~m}$ during the day.

860 Solid line represents the proportion without a mortality hypothesis and dashed line, with a annual mortality rate (3.8) hypothesis. The black rectangle is the estimated spawning season for the European eel. 

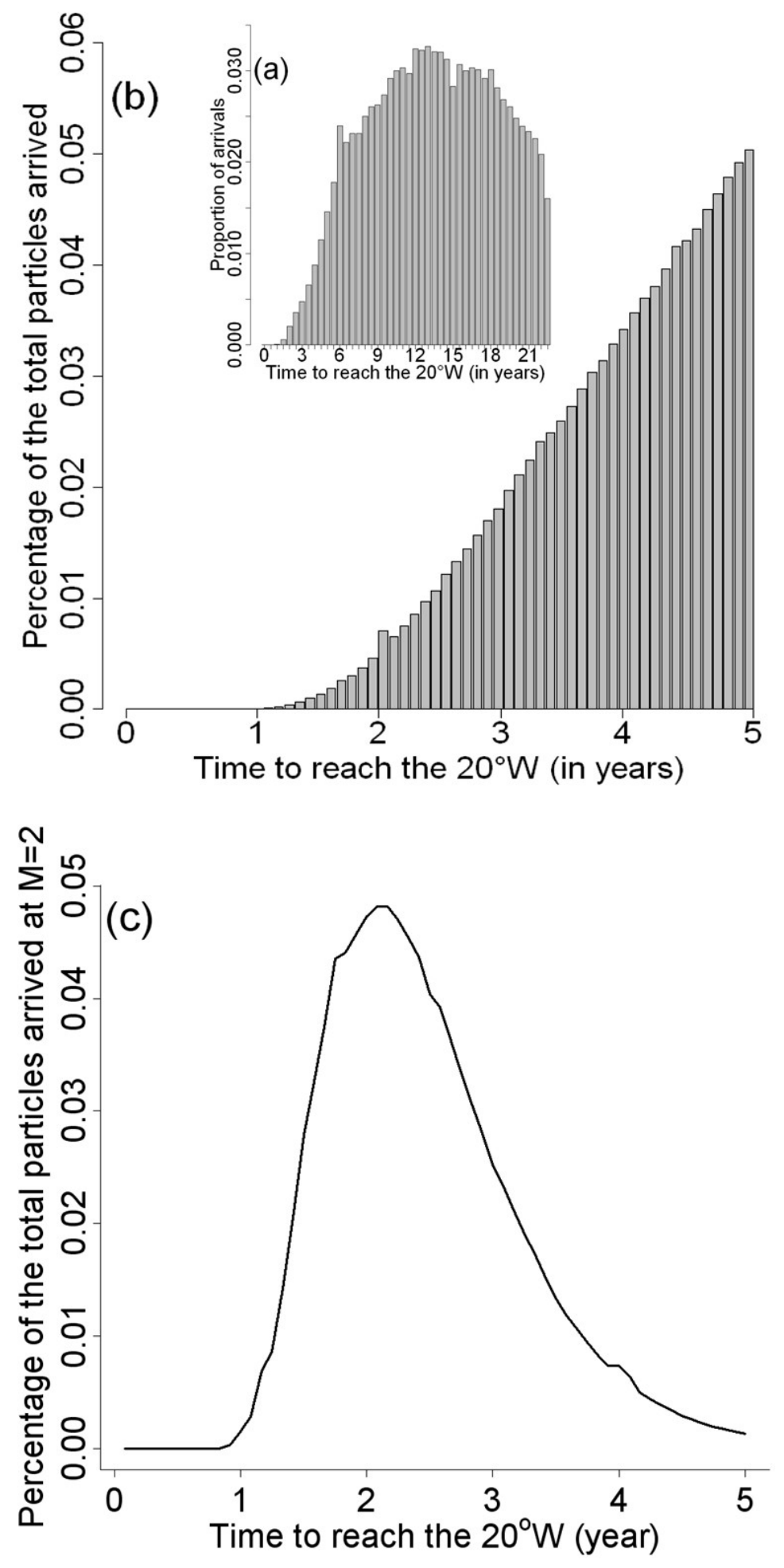

Figure 7: (a) Histogram of the time needed to reach $20^{\circ} \mathrm{W}$ for particles released in the 865 Sargasso Sea every 15 days during the year 1961 and drifting for a maximum of 23 years. Each bar represents the percentage of all particles reaching the $20^{\circ} \mathrm{W}$ over different time classes (b) The same histogram truncated at 5 years. (c) Plot of the same histogram when applying an annual mortality (M) of 2. Figures used results of the fixed-depth experiment. 

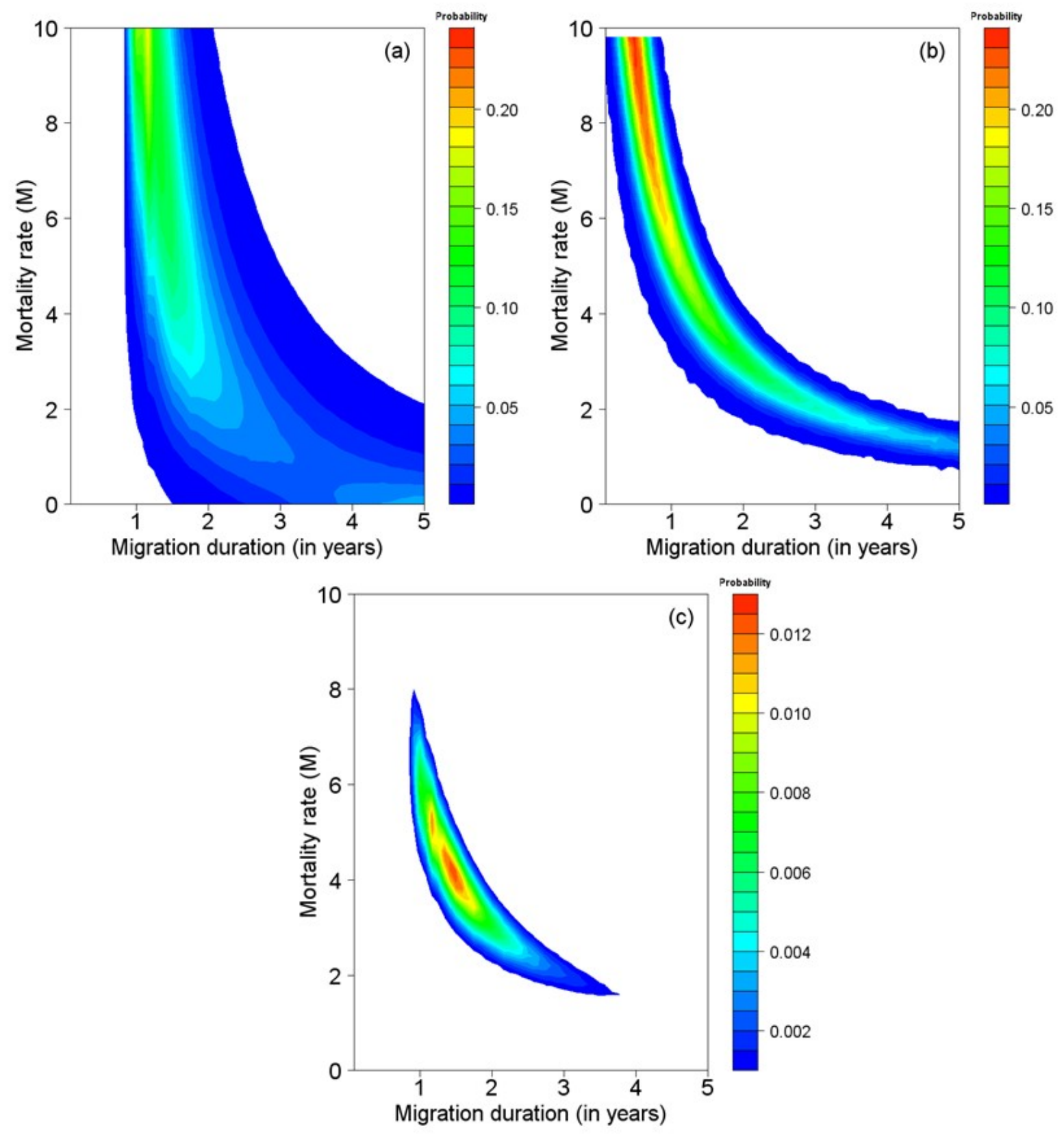

870 Figure 8: (a) Probability distribution of the migration durations estimated by Lagrangian simulations for different annual mortalities (denoted $\pi_{L}(M, d)$ in the text). This figure shows the results of experiments at fixed-depth. (b) Probability distribution of migration durations estimated by the steady state hypothesis of the population (see Eq. 10) for different annual mortalities (denoted $\pi_{E}(M, d)$ in the text). (c) Intersection of the probability

875 distribution of migration durations estimated by the steady state hypothesis of the population and by the Lagrangian simulations (denoted $\pi(M, d)$ in the text) 


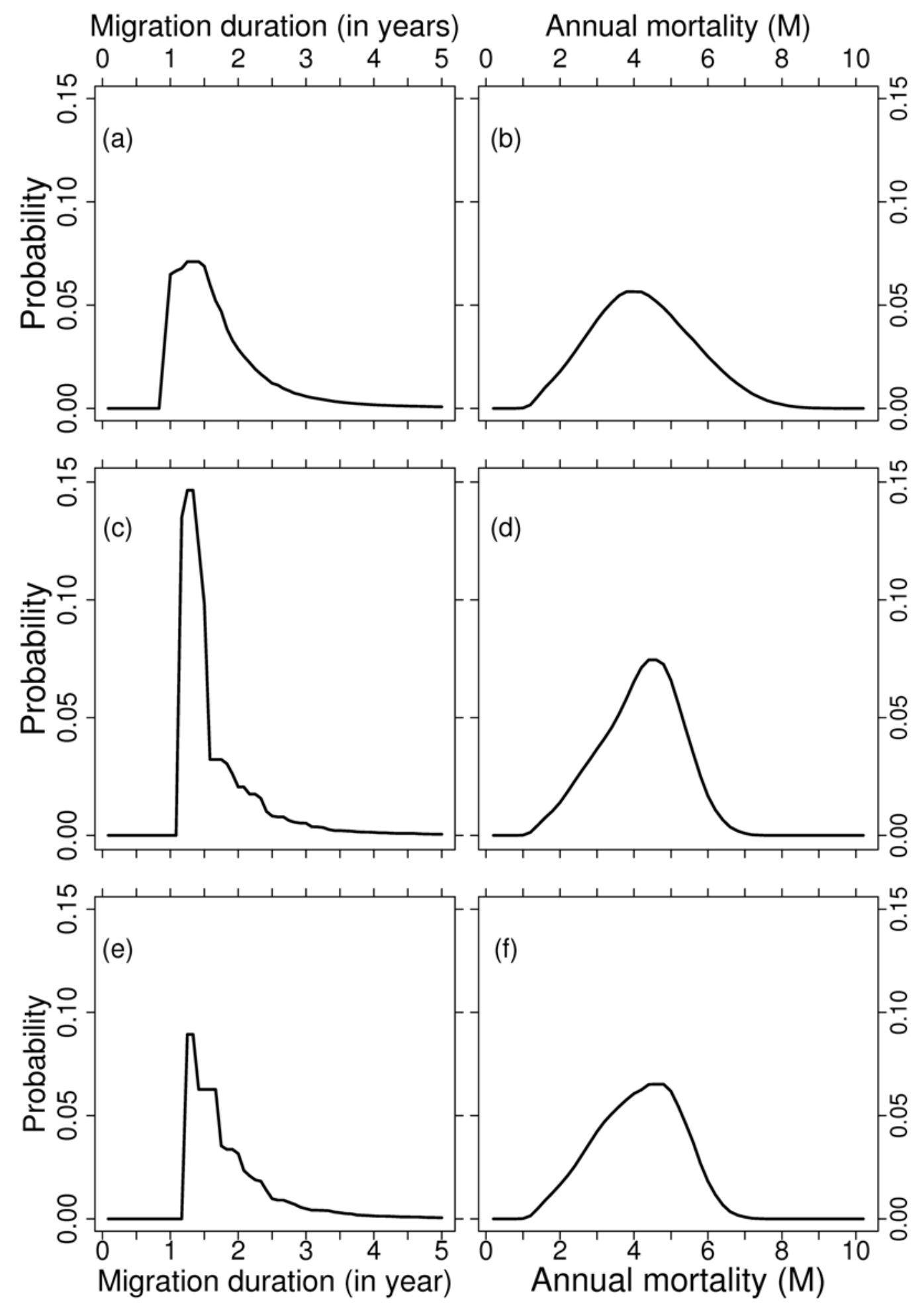

Figure 9: Marginal distributions of the migration duration estimated using Eq. 10 for (a) the fixed depth experiments, (c) the vertical migration experiments, (e) and the faster current choice experiments, (b) the annual mortality estimated using Eq. 10 for the fixed depth experiments, (d) the vertical migration experiments and (f) and the faster current choice experiments. 


\section{List of Tables}

Table I. Estimates of the different parameters given in Eq. 7. Fec is the fecundity of female 885 eels (number of eggs per individual), $\xi$ the hatching rate, $\beta$ the survival rate of glass eels, $\gamma$ the survival rate of adult eels (continental stage) that equals to $\mathrm{e}^{-M a . d a}$, where $M_{a}$ is the mortality rate and $d_{a}$ is the age of silver eel before seaward migration, and $\eta$ is the rate of silver eels that succeed in crossing the Atlantic Ocean and mating.

Table II. Elasticity of the estimated mean migration duration and mortality regarding the 890 different parameters given in Eq. 4.2 for each experiment. Symbols as in Table I. 
Table I: Estimates of the different parameters given in Eq. 7. Fec is the fecundity of female eels (number of eggs per individual), $\xi$ the hatching rate, $\beta$ the survival rate of glass eels, $\gamma$ the survival rate of adult eels (continental stage) that equals to $\mathrm{e}^{-M a d a}$, where $M_{a}$ is the mortality rate and $d_{a}$ is the age of silver eel before seaward migration, and $\eta$ is the rate of silver eels that succeed in crossing the Atlantic Ocean and mating.

\begin{tabular}{ccl}
\hline Parameter & Range of value & \multicolumn{1}{c}{ Source } \\
\hline \hline Fec & $9.10^{5}-2.6 .10^{6}$ & Boëtius \& Boëtius (1980) \\
(\# of eggs) & $1.10^{6}(55 \mathrm{~cm}), 4-5.10^{6}(95 \mathrm{~cm})$ & B. Knights (pers. comm.) \\
& $1.49 .10^{6}\left(9.10^{4}-6.10^{6}\right)(39-99 \mathrm{~cm})$ & Bark et al. $(2007)$ \\
\hline$\zeta$ & $10-30 \%^{\mathrm{a}}$ & Furuita et al. $(2003)$ \\
\hline \multirow{2}{*}{$\beta^{\mathrm{b}}$} & $20-40 \%^{\mathrm{a}}$ & Unuma et al. $(2004)$ \\
\hline $\mathrm{M}_{\mathrm{a}}$ & $17.3-23.1 \%$ & Berg \& Jorgensen $(1994)$ \\
$\mathrm{d}_{\mathrm{a}}$ & $3-27 \%$ & C. Briand (pers. comm..) \\
& $26-32 \%$ & Moriarty \& Dekker (1997) \\
\hline$\eta$ & 0.14 per year & Dekker (2000) \\
\hline \multirow{2}{*}{$\eta$} & $2-20$ years & Tesch (2003) \\
& $8-18$ years & Bertin (1956) \\
\hline \multirow{2}{*}{$30 \%$} & - \\
\hline
\end{tabular}

${ }^{a}$ estimates for the Japanese eel

${ }^{\mathrm{b}}$ for the stage 
Table II: Elasticity of the estimated mean migration duration and mortality regarding the different parameters given in Eq. 4.2 for each experiment. Symbols as in Table I.

\begin{tabular}{lcccccc}
\hline Variable and simulation design & Fec & $\xi$ & $\beta$ & $\mathrm{M}_{\mathrm{a}}$ & $\mathrm{d}_{\mathrm{a}}$ & $\eta$ \\
\hline \hline Mean migration duration & & & & & & \\
\hline Exp. 1 (fixed-depth) & 0.07 & 0.07 & 0.07 & -0.16 & -0.16 & 0.07 \\
\hline Exp. 2 (vertical migration) & 0.06 & 0.05 & 0.05 & -0.11 & -0.11 & 0.05 \\
\hline Exp. 3 (fastest current choice) & 0.06 & 0.04 & 0.05 & -0.12 & -0.12 & 0.05 \\
\hline Mortality & & & & & & \\
\hline Exp. 1 (fixed-depth) & -0.24 & -0.22 & -0.22 & 0.49 & 0.49 & -0.22 \\
\hline Exp. 2 (vertical migration) & -0.22 & -0.19 & -0.20 & 0.45 & 0.45 & -0.20 \\
\hline Exp. 3 (fastest current choice) & -0.23 & -0.21 & -0.20 & 0.46 & 0.46 & -0.21 \\
\hline
\end{tabular}

900 